\title{
DETERMINANTES MACROECONÔMICOS DO SPREAD BANCÁRIO NO BRASIL: TEORIA E EVIDÊNCIA RECENTE*
}

\author{
José Luís da Costa Oreiro ${ }^{\S}$ \\ Luiz Fernando de Paula \\ Guilherme Jonas Costa da Silva ${ }^{\dagger}$ \\ Fábio Hideki Ono
}

\begin{abstract}
RESUMO
No Brasil, em razão do sucesso do processo de estabilização de preços, da maior abertura e integração ao mercado financeiro internacional e, mais recentemente, da adoção de um regime de taxa de câmbio flutuante, esperava-se que os spreads bancários iriam, em algum grau, convergir para os níveis internacionais, o que acabou por não acontecer. De fato, um dos principais fatores que impedem o crescimento do crédito no Brasil - cuja relação crédito/PIB tem caído de forma acentuada de 1994 aos dias de hoje - são as elevadíssimas taxas de juros dos empréstimos que têm sido praticadas no País. O presente artigo tem por objetivo aprofundar a discussão sobre a determinação do spread bancário no Brasil, procurando mostrar que os determinantes macroeconômicos são fatores importantes a serem considerados na explicação do comportamento do spread no País. Para tanto, realiza-se uma análise de regressão múltipla com o intuito de identificar as variáveis macroeconômicas que podem estar influenciando direta ou indiretamente o spread no Brasil no período 1994/2003. $\mathrm{O}$ artigo apresenta evidências de que a elevada volatilidade da taxa de juros e seu nível são os determinantes macroeconômicos principais do elevado spread bancário no Brasil.
\end{abstract}

Palavras-chave: spread bancário, setor bancário brasileiro, economia brasileira.

\begin{abstract}
Due to the successful implementation of the price stabilization programme (Real Plan), the greater international financial integration and, more recently, the adoption of a floating exchange rate regime, it was expected in Brazil a sharp decline of the banking interest spreads converging to the international levels. However, such a reduction did not materialized. Indeed, one of the main factors to why the ratio total credit over GDP is still low in Brazil is the very high loan interest rates. The paper aims to at analyze the macroeconomic determinants of banking spread in Brazil. For this purpose, we make use of a multiple regression analysis with the objective to find what macroeconomic variables are determining, directly or indirectly, the banking spread in the period 1994-2003. The results show that the high volatility of the short-term interest rate (Selic) and its level are the main macroeconomic determinants of the banking spread in Brazil.
\end{abstract}

Key words: banking spread, Brazilian banking sector, Brazilian economy.

JEL classification: E43, E44, E51.

* O apoio do PRONEX/CNPq/FAPERJ é reconhecido. Os autores agradecem as sugestões feitas por Frederico Gonzaga Jayme (CEDEPLAR/UFMG), José Gabriel Porcile Meireles (PPGDE/UFPR) e de um parecerista anônimo, isentando-os, como de praxe, por erros e omissões remanescentes.

$\S$ Professor do Departamento de Economia da Universidade Federal do Paraná (UFPR), Diretor do Centro de Pesquisas Econômicas (CEPEC) da UFPR e pesquisador do CNPq. Endereço para contato: UFPR/Departamento de Economia, Av Prof. Lothario Meissner 632, Sala SA. TEN.36, Jardim Botânico, 80210-170, Curitiba, PR. E-mail: joreiro@ufpr.br. Página pessoal: http://www. joseluisoreiro.ecn.br.

a. Professor da Faculdade de Ciências Econômicas da Universidade do Estado do Rio de Janeiro (UERJ) e pesquisador do CNPq. Endereço para contato: FCE/UERJ, Rua São Francisco Xavier, 524 sala 8039F, 20550-013, Rio de Janeiro, RJ. E-mail: luizfpaula@terra.com.br. Página pessoal: http://paginas.terra.com.br/educacao/luizfpaula.

$\dagger$ Mestre em Desenvolvimento Econômico da Universidade Federal do Paraná (UFPR) e doutorando em Economia do CEDEPLAR/UFMG.E-mail: guilhermejonas@yahoo.com.br.

\$ Mestre em Desenvolvimento Econômico da Universidade Federal do Paraná (UFPR). E-mail: fabiohono@gmail.com.

Recebido em outubro de 2004. Aprovado em outubro de 2006. 


\section{INTRODUÇÃo}

No Brasil, em razão do sucesso de processo de estabilização de preços, da maior abertura e integração ao mercado financeiro internacional e, mais recentemente, da adoção de um regime de taxa de câmbio flutuante, esperava-se que os spreads bancários - a diferença entre a taxa de juros cobrada aos tomadores de crédito e a taxa de juros paga aos depositantes pelos bancos - iria, em algum grau, convergir para os níveis internacionais. Há, contudo, um certo desapontamento com relação aos resultados alcançados. Apesar da queda da taxa de juros que ocorreu a partir de meados de 1999, o spread bancário no Brasil ainda se mantém em patamares elevadíssimos em termos internacionais, situando-se ao redor de $40 \%$ nos últimos anos. ${ }^{1}$

De fato, um dos principais fatores que impedem o crescimento do crédito no Brasil - cuja relação crédito/PIB tem caído de forma acentuada de 1994 aos dias de hoje - são as elevadíssimas taxas de juros dos empréstimos que têm sido praticadas no País, que explica, ao menos em parte, a alta rentabilidade dos grandes bancos varejistas. Por sua vez, o baixo nível de crédito no Brasil é um dos fatores que têm contribuído para que a economia cresça abaixo de seu potencial.

Embora já existam alguns estudos acadêmicos sobre a determinação do spread no Brasil, a explicação sobre o nível do elevado spread bancário no País ainda é uma questão em aberto. Alguns estudos procuraram aferir se o spread bancário elevado estaria relacionado à baixa concorrência existente no setor, mas os resultados estão longe de ser conclusivos. ${ }^{2}$ Por outro lado, tem sido bastante veiculado - por exemplo, pela Federação Brasileira de Bancos (FEBRABAN) - que os altos spreads resultam fundamentalmente do crowding out do governo no mercado de títulos, em razão de sua elevada dívida, dos níveis elevados do compulsório sobre os depósitos dos bancos, da tributação excessiva sobre as operações de crédito e ainda do elevado volume de créditos direcionados, tudo isto fazendo com que os bancos tenham menos recursos para emprestar e a um custo artificialmente mais alto. ${ }^{3}$

Um estudo no Brasil - que passou despercebido na discussão brasileira -, realizado por Afanasieff et al. (2002), fugiu à regra. Os autores, utilizando a abordagem de dois passos de Ho e Saunders (1981), ao investigar se os fatores macro e microeconômicos são relevantes para explicar o comportamento do spread no País, sugerem, a partir dos resultados obtidos, que variáveis macroeconômicas - como a taxa básica de juros e o crescimento do produto - são os fatores mais relevantes para explicar tal comportamento. Esse resultado, contudo, não é surpreendente, considerando que outros estudos internacionais apresentam evidências de que a incerteza do ambiente econômico que envolve os bancos parece ser uma importante causa dos spreads bancários. (Saunders e Schumacher, 2000; Brock e Suarez, 2000). No caso do Brasil, dada a instabilidade macroeconômica que tem caracterizado a economia desde o início dos anos 1980, é de se esperar que os fatores macroeconômicos tenham uma importância fundamental na determinação do spread.

O presente artigo tem por objetivo aprofundar a discussão sobre a determinação do spread bancário no Brasil, procurando, em particular, aprofundar a análise dos determinantes macroeconômicos do spread no período recente. Para tanto, o artigo está estruturado em 6 seções, além desta introdução. Na seção 2 é realizada uma revisão da literatura sobre os determinantes do spread, enquanto que a seção 3 avalia brevemente alguns estudos de caso. A seção 4, por sua vez, efetua uma análise da evolução e dos determinantes do spread bancário no Brasil. Já na seção 5 realiza-se uma análise de regressão múltipla com o intuito de identificar as variáveis macroeconômicas que podem

1 Segundo Afanasieff et al. (2002, p. 192), o spread bancário em 2000 era de 11,96\% no México, 2,75\% na Argentina, 5,64\% no Chile, $2,77 \%$ nos EUA e 3,15\% na Zona do Euro.

2 Ver, por exemplo, a resenha sobre concorrência e spread bancário no Brasil feita por Nakane (2003).

3 Para uma análise sobre os argumentos da Febraban em relação ao spread bancário, ver Mendes (2004). 
estar influenciando direta ou indiretamente o spread no País no período 1994/2003. A seção 6 - a título de conclusão - sumaria os principais resultados encontrados no artigo.

\section{OS DETERMINANTES DO SPREAD BANCÁRIO: UMA REVISÃO DA LITERATURA CON- VENCIONAL}

A literatura teórica convencional sobre os determinantes do spread bancário ${ }^{4}$ tem se desenvolvido em torno de duas principais abordagens. Na primeira abordagem ("modelos de monopólio"), cujo trabalho seminal é Klein (1971), o banco é visto como uma firma cuja principal atividade é a produção de serviços de depósitos e de empréstimos por intermédio do emprego de uma tecnologia de produção de serviços bancários, representada por uma função custo do tipo $C(D, L){ }^{5}$ A atividade da firma bancária se desenvolve, via de regra, num ambiente de mercado que é caracterizado pela presença de concorrência monopolista ou imperfeita, tanto no mercado de crédito como no mercado de depósitos. Isto significa que o banco tem poder de monopólio na fixação da taxa de juros em pelo menos um dos mercados em que opera, normalmente o mercado de crédito, comportando-se como um formador de preços (price setter). Este poder de monopólio explicaria a escala de operação e as estruturas ativa e passiva do banco, levando em conta que as decisões de um banco individual seriam capazes de afetar as taxas que remuneram os componentes do passivo, assim como aqueles integrantes do ativo bancário. Portanto, o spread bancário reflete fundamentalmente - nesta abordagem - o "grau de monopólio" do banco, ou seja, a sua capacidade de cobrar um preço maior do que o custo marginal de produção dos serviços por ele oferecidos.

Nesse contexto, seja $r$ a taxa de juros prevalecente no mercado interbancário, $r_{l}$ a taxa de juros cobrada dos empréstimos feitos pelo banco, $r_{d}$ a taxa de juros paga pelos depósitos feitos no banco, $\alpha$ as reservas compulsórias como proporção do volume de depósitos do banco, $\varepsilon_{L}$ a elasticidade-juros da demanda de empréstimos, $\varepsilon_{D}$ a elasticidade-juros da oferta de depósitos, $C^{\prime}{ }_{L}$ o custo marginal dos serviços de empréstimos e $C^{\prime}{ }_{D}$ o custo marginal dos serviços de depósitos. Supondo que o banco é neutro ao risco e que o seu comportamento é pautado pela maximização de lucros, pode-se demonstrar que a margem ótima de intermediação nos empréstimos e nos depósitos é dada por: ${ }^{7}$

$$
\begin{aligned}
& \frac{1}{\varepsilon_{L}^{*}}=\frac{r_{L}^{*}-\left(r+C_{L}^{\prime}\right)}{r_{L}^{*}} \\
& \frac{1}{\varepsilon_{D}^{*}}=\frac{r(1-\alpha)-C_{D}^{\prime}-r_{D}^{*}}{r_{D}^{*}}
\end{aligned}
$$

As equações (1) e (2) estabelecem que a firma bancária, atuando em condições de concorrência monopolista, fixa os preços de seus serviços de empréstimos e de depósitos de modo a que os índices de Lerner sejam iguais ao inverso da elasticidade-juros das funções de demanda de emprés-

4 Para o leitor interessado numa abordagem não-convencional da firma bancária ver, entre outros, Paula (1999) e Oreiro (2005).

5 Em que $D$ é o volume de depósitos "produzido" pelo banco e $L$ é o volume de empréstimos. É feita a suposição tradicional de que o custo marginal dos empréstimos e dos depósitos é positivo e crescente, ou seja, $\frac{\partial C}{\partial D}>0 ; \frac{\partial C}{\partial L}>0 ; \frac{\partial^{2} C}{\partial D^{2}}>0 ; \frac{\partial^{2} C}{\partial L^{2}}>0 \quad$ (cf. Freixas
e Rochet, 1999, p. 67-68).

6 Isso significa dizer que o banco só se preocupa com o valor esperado dos seus lucros, não dando importância à dispersão dos lucros em torno do valor esperado. Neste caso, objetivo do banco será a maximização do lucro esperado, em vez da maximização da utilidade esperada do lucro.

7 Ver Freixas e Rochet (1999, cap.3). 
timos e de oferta de depósitos. Daqui se segue que quanto menos sensíveis forem as funções de demanda de empréstimos e de oferta de depósitos a variações da taxa de juros, maior será a margem de intermediação dos bancos, tanto nas operações de empréstimos como na captação de depósitos e, portanto, maior o spread bancário.

Uma implicação importante dessa abordagem é que a eliminação das restrições governamentais referentes à área geográfica de atuação dos bancos pode contribuir para a redução do spread bancário. Isto porque a presença de vários bancos numa mesma região atua no sentido de aumentar o grau de substituibilidade entre os serviços de depósitos oferecidos pelos bancos. Dessa forma, a elasticidade-juros da oferta de depósitos deve aumentar, forçando os bancos a elevar a taxa de juros para a captação de depósitos (cf. Klein, 1971, p. 217). Um resultado semelhante poderia, a princípio, ser obtido por intermédio da eliminação das barreiras legais para a atuação de bancos estrangeiros num dado país.

Se a estrutura de mercado for do tipo oligopolista, quer na concessão de empréstimos como na captação de recursos, então a margem ótima de intermediação dos empréstimos e dos depósitos é dada por: ${ }^{8}$

$$
\begin{aligned}
& \frac{s}{\varepsilon_{L}^{*}}=\frac{r_{L}^{*}-\left(r+C_{L}^{\prime}\right)}{r_{L}^{*}} \\
& \frac{s}{\varepsilon_{D}^{*}}=\frac{r(1-\alpha)-C_{D}^{\prime}-r_{D}^{*}}{r_{D}^{*}}
\end{aligned}
$$

Em que: $s$ é o market share do $n$-ésimo banco.

Com base nas equações (3) e (4) podemos constatar que a margem de intermediação do banco nas operações de empréstimo e de captação de depósitos é uma função crescente do market share do banco. Desta forma, uma redução do número de firmas bancárias em razão, por exemplo, da ocorrência de um processo de fusões e aquisições de bancos, irá resultar num aumento da concentração bancária e, portanto, num aumento das margens de intermediação. Daqui se segue que uma das previsões desse modelo é que o spread bancário é uma função crescente do grau de concentração do setor bancário como um todo.

Na segunda abordagem, cujo trabalho seminal é Ho e Saunders (1981), ${ }^{9}$ o banco é visto não como uma firma, mas como um simples intermediário entre o tomador final (as firmas) e o emprestador último (as famílias). Esta atividade de intermediação está, no entanto, sujeita a dois tipos de incerteza. Em primeiro lugar, existe a incerteza gerada pela falta de sincronização entre depósitos e empréstimos. Esta falta de sincronização impõe um risco de taxa de juros para o banco. Para que possamos entender o porquê disto, consideremos que o banco se defronte com uma demanda inesperadamente alta de empréstimos, demanda esta superior ao volume recebido de depósitos e de suas reservas livres. Neste caso, ele se verá obrigado a financiar a demanda excessiva de crédito no mercado interbancário, incorrendo, assim, num risco de refinanciamento caso haja um aumento da taxa de juros (cf. Maudos e Guevara, 2003, p. 4). Por outro lado, se o banco se defrontar com uma oferta inesperadamente alta de depósitos - cuja magnitude seja superior ao volume de empréstimos concedido pelo banco no mesmo período -, ele deverá então aplicar esse excesso de recursos no

8 Ver Freixas e Rochet (1999, cap. 3).

9 Extensões do modelo básico de Ho e Saunders foram feitas por Allen (1988), McChane e Sharpe (1985), Angbazo (1997) e Maudos e Guevara (2003). No que se segue iremos trabalhar com a extensão mais recente desenvolvida pelos últimos autores. 
mercado interbancário. Desta forma, o banco estará incorrendo num risco de reinvestimento caso haja uma redução da taxa de juros. (Ibid, p.4).

Em segundo lugar, a atividade de intermediação expõe o banco à incerteza quanto à taxa de retorno dos empréstimos. Esta incerteza decorre do fato de que uma parte dos empréstimos não será devolvida em razão da inadimplência voluntária ou não dos tomadores. O porcentual de empréstimos em default, contudo, não é uma variável conhecida ex-ante pelo banco, que pode apenas estimar uma probabilidade de default.

Uma característica comum entre as abordagens de Klein e Ho e Saunders é a suposição de que os bancos têm poder de mercado, ou seja, assume-se em ambas as abordagens que os bancos têm liberdade para fixar o nível da taxa de juros cobrada sobre as operações de crédito e a taxa de juros que é paga sobre a captação de depósitos. No entanto, ao contrário da abordagem de Klein, é suposto que o banco é um agente avesso ao risco na abordagem de Ho e Saunders. ${ }^{10}$ Em outras palavras, o objetivo do banco não é a maximização do lucro esperado, mas sim a maximização da utilidade esperada do lucro. Neste contexto, demonstra-se que o spread ótimo $\left(s^{*}\right)$ é dado por: ${ }^{11}$

$$
\left.s^{*}=\frac{1}{2}\left(\frac{\alpha_{D}}{\beta_{D}}+\frac{\alpha_{L}}{\beta_{L}}\right)+\frac{1}{2}\left(\frac{C(L)}{L}+\frac{C(D)}{D}\right)-\frac{1}{4} \frac{U^{\prime \prime}(\bar{W})}{U^{\prime}(\bar{W})}\left[\left(L+2 L_{0}\right) \sigma_{L}^{2}+(L+D) \sigma_{M}^{2}+2\left(M_{0}-L\right) \sigma_{L M}\right)\right]
$$

Em que: $\alpha_{D}$ é o intercepto linear da função de probabilidade de chegada de um depósito no banco, $\beta_{D}$ é a sensibilidade da probabilidade de chegada de um depósito no banco às variações da taxa de juros de captação, $\alpha_{L}$ é o intercepto linear da função de chegada de um pedido de empréstimo no banco, $\beta_{L}$ é a sensibilidade da probabilidade de chegada de um pedido de empréstimo às variações da taxa de juros cobrada sobre as operações de crédito; $C(L) / L$ é o custo médio das operações de crédito; $C(D) / D$ é o custo médio das operações de captação de depósitos; $\bar{W}$ é o estoque final de riqueza do banco; $-\left[\frac{U^{\prime \prime}(\bar{W})}{U(\bar{W})}\right]$ é o grau de aversão absoluta ao risco do banco ${ }^{12} ; \sigma_{L}^{2}$ é o

desvio padrão da taxa de retorno dos empréstimos (medida do risco de crédito do banco); $\sigma^{2}{ }_{M}$ é o desvio padrão da taxa de retorno das aplicações/empréstimos no mercado interbancário (medida do risco de taxa de juros do banco); $\sigma_{L M}$ é a covariância entre o risco de crédito e o risco de taxa de juros; $L_{0}$ é o estoque inicial de empréstimos do banco; $M_{0}$ é a posição líquida inicial do banco no mercado interbancário.

Com base na equação (5), podemos concluir que os determinantes do spread bancário são:

- A estrutura competitiva dos mercados: quanto maior a elasticidade-juro da demanda de empréstimos e da oferta de depósitos (ou seja, quanto menores forem os valores de $\beta_{L}$ e $\beta_{D}$ ), menor será o spread ótimo.

- O custo médio operacional do banco: $\left[\frac{C(L)}{L}+\frac{C(D)}{D}\right]$

10 A justificativa teórica da hipótese de aversão ao risco pode ser encontrada em Angbazo (1997). Em suas palavras: "Risk aversion assumption is justified on two grounds. First, risk aversion is crucial to justify the persistence of interest margins. Within the dealership framework the margin would always exist because of uncertain liquidity needs of borrowers and depositors (...) The second justification for risk aversion in the model is that it ensures a finite bank size, as well as the existence of riskless investments in money market instruments. Without risk aversion, there is no limit to the extent that banks may engage in arbitrage. Banks will expand ad infinitum until the margin is completely eliminated. Traditional explanations for risk aversion behavior in banks include (1) management's inability to diversify its human capital; (2) insufficient owner diversification; (3) incentive problems such as moral hazard and adverse selection which are associated with government regulation (e.g deposit insurance, failure resolution mechanism, etc). These regulations in turn require banks which enjoy protection to limit risk; and (4) bankruptcy cost resulting from partial or complete default." (1997, p, 58, n. 4).

11 Ver Maudos e Guevara (2003).

12 Note que $U^{\prime}()>$.0 e $U^{\prime \prime}()<$.0 em razão da hipótese de aversão ao risco. 
- O grau de aversão ao risco do banco: $-\left[\frac{U^{\prime \prime}(\bar{W})}{U(\bar{W})}\right]$

- A volatilidade da taxa de juros dos empréstimos interbancários: $\sigma_{M}^{2}$

- O risco de crédito: $\sigma_{L}^{2}$

- A covariância entre o risco de crédito e o risco de taxa de juros: $\sigma_{L M}$

- O tamanho médio das operações de crédito e de depósitos do banco: $(L+D)$.

Um aspecto importante da abordagem Ho e Saunders é que ela abre um espaço para a influência de variáveis macroeconômicas na determinação do spread bancário (cf. Saunders e Schumacher, 2000, p. 815). De fato, a volatilidade da taxa de juros cobrada sobre os empréstimos realizados no mercado interbancário é reflexo direto da estabilidade macroeconômica do país. Quanto mais instável for a economia de um dado país - por exemplo, quanto maior for a variabilidade da taxa de inflação e da taxa de câmbio -, maior será a volatilidade resultante da taxa básica de juros ${ }^{13}$ e, por conseguinte, maior deverá ser o spread bancário. ${ }^{14}$ Nesse contexto, o spread pode ser reduzido por intermédio de políticas macroeconômicas que diminuíssem a volatilidade da taxa básica de juros.

A instabilidade macroeconômica pode afetar o spread bancário por mais dois outros canais. O primeiro deles é o grau de aversão ao risco. Com efeito, a aversão ao risco dos bancos deve, em alguma medida, refletir a própria instabilidade do ambiente de mercado no qual eles operam. Quanto mais instável for esse ambiente, maior deve ser a aversão ao risco dos bancos. Sendo assim, um país que possua um histórico de grande instabilidade macroeconômica deverá possuir bancos que tenham um elevado grau de aversão ao risco.

O segundo canal é a covariância entre o risco de taxa de juros e o risco de crédito. Uma elevada volatilidade da taxa básica de juros deve se traduzir, em alguma medida, numa alta variabilidade do nível de produção real. Neste contexto, os lucros das firmas também deverão apresentar uma grande variabilidade, o que aumenta a probabilidade de default nos momentos em que os lucros estiverem abaixo do seu valor esperado. Daqui se segue que a instabilidade macroeconômica se reflete não apenas numa alta volatilidade da taxa de juros, mas também num elevado risco de crédito, ou seja, essa instabilidade gera uma grande covariância entre o retorno dos empréstimos e o retorno das aplicações no mercado interbancário. Com base em (5), observa-se que quanto maior for essa covariância, maior será o spread bancário.

Uma observação final é necessária a respeito da equação (5). O spread determinado por essa expressão deve ser entendido como o spread bancário puro (cf. Maudos e Guevara, 2003, p.7). Na prática existem outras variáveis que explicam a margem de intermediação dos bancos, mas cuja incorporação a um modelo teórico é difícil, quando não impossível. Essas variáveis estão relacionadas com os aspectos institucionais e regulatórios da atividade bancária. Daqui se segue que a margem efetiva de intermediação bancária é composta por dois elementos, a saber: o spread bancário puro $\left(s^{*}\right)$ e a margem "suja" de intermediação $(f)$, explicada por fatores institucionais e regulatórios.

13 Principalmente no caso em que a política monetária é conduzida com base no sistema de metas de inflação.

14 O risco de taxa de juros está relacionado ao risco de um banco ter um spread pequeno ou mesmo negativo em suas operações de intermediação financeira, devido às oscilações das taxas de juros de mercado: no momento de refinanciamento do ativo pode ocorrer uma variação nos custos de captação que seja incompatível com o rendimento esperado das aplicações. Conseqüentemente, os lucros podem ser reduzidos caso um banco com uma grande quantidade de ativos com taxas de juros fixas venha a se deparar com um grande aumento nos custos de captação de curto prazo. 


\section{ESTUdOS DE CASOS INTERNACIONAIS}

Nos últimos anos, uma vasta literatura empírica sobre os determinantes do spread bancário tem sido desenvolvida. Uma primeira vertente dessa literatura tem procurado testar empiricamente o modelo teórico de spread bancário desenvolvido por Ho e Saunders (1981). Alguns dos trabalhos mais importantes nessa linha de pesquisa são McShane e Sharpe (1985), Angbazo (1997), Saunders e Schumacher (2000) e Maudos e Guevara (2003).

A maior parte desses trabalhos utiliza a metodologia de estimação do "spread puro" desenvolvida pioneiramente por Ho e Saunders. Essa metodologia parte do pressuposto de que o spread efetivo é composto pelo spread puro ajustado para cima ou para baixo pelo pagamento implícito de juros (isenção de tarifas para certas classes de clientes), pelo custo de oportunidade de retenção das reservas e pelas exigências de capital próprio advindas das normas de regulação e de supervisão bancária. Nesse contexto, o spread puro é estimado por intermédio de um processo em duas etapas. $\mathrm{Na}$ primeira etapa roda-se uma regressão cross-section da margem líquida de intermediação de cada banco do país selecionado em um determinado ano (cf. Saunders \& Schumacher, 2000). Essa equação é dada por:

$$
N I M_{i c}=\gamma_{c}+\sum_{i} \delta_{j} X_{j i c}+u_{i}
$$

Em que: $N I M_{i c}$ é a margem de intermediação do banco $i$ no país $c$ no período $t ; X_{j i c}$ é o vetor de variáveis de controle (pagamento implícito de juros, custo de oportunidade das reservas e requerimento de capital próprio) do banco $i$ no país $c$ no período $t ; \gamma_{c}$ é a constante da regressão, a qual é uma estimativa do spread puro para todos os bancos do país $c$ no período $t$.

Nesta primeira etapa roda-se a equação (6) para cada país da amostra selecionada ao longo do período de análise. No artigo de Saunders e Schumacher (2000), por exemplo, utiliza-se uma amostra com 746 bancos de sete países (Estados Unidos, Alemanha, França, Reino Unido, Itália, Espanha e Suíça) no período 1988-1995. Ao se repetir essas regressões cross section para os anos 1-8 do período em consideração obtêm-se oito estimativas de spread puro para cada país. Desta forma, obtêm-se uma série de oito períodos para o spread puro.

As estimativas de spread puro obtidas ao longo da primeira etapa variam ao longo do tempo e entre países. Sendo assim, na segunda etapa roda-se uma regressão com dados em painel das estimativas do spread puro obtidas na primeira etapa contra uma série de variáveis que refletem a estrutura de mercado e os riscos da atividade de intermediação financeira. A equação a ser estimada é dada por:

$$
\gamma_{t c}=\theta_{0}+\sum_{c-1} \eta_{c}+\theta_{1} \sigma_{c}
$$

Em que: $\gamma_{t c}$ é a série de tempo de spread puro $(\mathrm{t}=1, \ldots, 8)$ para 7 países $(\mathrm{c}=1, \ldots, 7) ; \eta_{c}$ é uma série de variáveis dummy que refletem os efeitos da estrutura de mercado sobre o spread; $\theta_{1}$ é a sensibilidade do spread puro aos efeitos do risco de intermediação, $\sigma_{c}$ é a volatilidade da taxa de juros prevalecente no mercado interbancário.

Essa metodologia tem a vantagem de separar a influência sobre o spread puro das variáveis macroeconômicas (como, por exemplo, a volatilidade da taxa de juros) da influência das variáveis microeconômicas (como, por exemplo, a estrutura de mercado do setor bancário).

Os resultados obtidos por Saunders e Schumacher (2000) foram os seguintes:

- Entre as variáveis microeconômicas, aquela que tem maior impacto sobre o spread bancário é o pagamento implícito de juros. Em outras palavras, os bancos compensam a renúncia de re- 
ceita na forma de isenção de tarifas com uma maior margem de intermediação financeira. O requerimento de capital próprio também apresentou uma influência positiva e estatisticamente significativa sobre o spread puro.

- A estrutura de mercado do setor bancário tem pouca influência sobre os spreads. Com efeito, apenas $0,20 \%$ das margens de intermediação podem, na média, ser explicadas pelo poder de mercado dos bancos.

- A volatilidade da taxa de juros tem um impacto positivo e estatisticamente significativo sobre o spread bancário. Isto significa que quanto maior for a volatilidade da taxa básica de juros, maior será, em média, o spread cobrado pelos bancos.

Uma outra linha de investigação empírica sobre os determinantes do spread bancário em nível mundial é conduzida por Demirgüç-Kunt e Huizinga (1999). Estes autores investigam os determinantes dos spreads por meio do uso de estatísticas bancárias desagregadas de 7.900 bancos comerciais de 80 países no período 1988-1995. As variáveis independentes utilizadas refletiram as características bancárias, as condições macroeconômicas, ${ }^{15}$ a taxação dos bancos, os depósitos compulsórios e a estrutura financeira geral, incluindo indicadores institucionais. A equação de regressão usada no estudo é dada por:

$$
I_{i j t}=\alpha_{0}+\alpha_{i} B_{i j t}+\beta_{j} X_{j t}+\gamma_{t} T_{t}+\delta_{j} C_{j}+\varepsilon_{i j t}
$$

Em que: $I_{i j t}$ é a margem líquida de intermediação ou a rentabilidade do banco $i$ no país $j$ no período $t$; $B_{i j t}$ é o vetor de características do banco $i$ no país $j$ no período $t, X_{j t}$ é o vetor de características do país $j$ no período $t ; T_{t}$ e $C_{t}$ são variáveis dummy para o período e o país, respectivamente; $\varepsilon_{i j t}$ é um resíduo aleatório.

Segundo os autores, os spreads bancários são influenciados positivamente pela relação entre o capital próprio e os ativos totais defasados, pela razão entre os empréstimos e os ativos totais, por uma variável dummy relativa ao controle estrangeiro, pelo tamanho do banco (medido pelos ativos totais), pela razão entre os custos indiretos e os ativos totais, pela taxa de inflação e pela taxa real de juros de curto prazo. Por outro lado, a razão entre os ativos que não rendem juros, como ativos fixos, e os ativos totais têm um impacto negativo sobre os spreads.

No referente às variáveis macroeconômicas, os autores concluem que a taxa de crescimento do PIB real e o PIB per capita não parecem ter, em nível mundial, qualquer impacto estatisticamente significativo sobre os spreads. A inflação, medida pelo deflator implícito do PIB, tem um impacto positivo, porém estatisticamente insignificante sobre a margem líquida de intermediação dos bancos. Por fim, a taxa real de juros tem um efeito positivo e estatisticamente significativo sobre os spreads, mas este efeito é menor nos países desenvolvidos do que nos países em desenvolvimento.

Uma análise empírica usando dados em painel sobre os determinantes do spread bancário nos países da América Latina é feita por Brock e Rojas-Suárez (2000). Nesse estudo os autores utilizam uma amostra de bancos de seis países latino-americanos (Argentina, Bolívia, Colômbia, Chile, México e Peru) no período 1992-1996. A principal conclusão do estudo é que a influência das variáveis microeconômicas - como, por exemplo, o risco de crédito e o requerimento de capital próprio - é condicional ao estado de solidez ou fragilidade dos sistemas bancários domésticos. Nesse contexto, observa-se que para o subgrupo de países latino-americanos com sistemas bancários fracos/inade-

15 As variáveis macroeconômicas incluem o PIB per capita, a taxa de crescimento do PIB real, a taxa de inflação e a taxa real de juros. 
quadamente regulados $^{16}$ o risco de crédito tem um impacto negativo e estatisticamente significativo sobre os spreads bancários. Em outras palavras, um aumento do porcentual de empréstimos em atraso é seguido por uma redução dos spreads. ${ }^{17}$ No que diz respeito ao requerimento de capital próprio, no caso do México e do Peru - ambos com sistemas bancários fracos - não se observa uma relação (positiva ou negativa) entre essa variável e o spread bancário.

As variáveis macroeconômicas também apresentaram um impacto diferenciado de acordo com o país. Desta forma, a volatilidade da taxa de juros apresentou um impacto positivo e forte sobre o spread bancário na Bolívia e no Chile, mas um efeito negligenciável no México. A taxa de crescimento do PIB real teve um impacto negativo sobre os spreads no Chile e na Argentina, e negligenciável nos demais países. Por fim, a taxa de inflação não teve impacto estatisticamente significativo em nenhum dos países estudados.

\section{PANORAMA GERAL DO SPREAD BANCÁRIO NO BRASIL}

\subsection{Uma breve contextualização histórica}

O período analisado na amostra selecionada (1994/2003) é interessante por um conjunto de razões. Em primeiro lugar, a economia brasileira, com a implementação do Plano Real, ainda que à custa de alguns desequilíbrios macroeconômicos, saiu de um contexto de alta para baixa inflação. Considerando que os bancos tinham mais de $30 \%$ de suas receitas derivadas dos ganhos com o float (cf. IBGE/DECNA, 1997), era de se esperar que o novo contexto resultasse em importantes mudanças no comportamento dos bancos. Isto de fato aconteceu num primeiro momento - mais especificamente no $2^{\circ}$ semestre de 1994 -, quando as operações de crédito ganham importância nas aplicações dos bancos, mas este comportamento se altera a partir do contágio da crise mexicana em 1995, que levou a uma ameaça de insolvência do setor bancário. Com o crescimento da dívida pública, a partir de 1997, os bancos rapidamente retornam à sua estratégia de flexibilidade patrimonial, que foi típica do período de alta de inflação, contraindo crédito e aumentando suas aplicações em títulos públicos, predominantemente indexados à taxa de overnight e à taxa de câmbio. (Paula et al., 2001). Assim, o governo brasileiro tem sido impelido a oferecer um hedge cambial e de taxa de juros para cobrir os elevados prêmios de risco para rolagem de sua dívida pública. O comportamento dos bancos - neste contexto - acaba por ter influência no spread bancário, uma vez que os bancos passam a ter nos títulos públicos uma alternativa de aplicação de menor risco em relação aos empréstimos ao setor privado, o que faz com que aumente o prêmio de risco nas suas operações de crédito.

Em segundo lugar, e relacionado ao anterior, a economia brasileira, em particular a partir de 1997, tem se caracterizado por uma tendência a semi-estagnação econômica e por movimento de stop-and-go, resultado de sua elevada vulnerabilidade externa em contexto de alta instabilidade nos mercados financeiros internacionais. Neste contexto, a arquitetura de política econômica vigente tem resultado em forte instabilidade em variáveis macroeconômicas chaves, como a taxa de juros e

16 Esse subgrupo é constituído por Argentina, Bolívia, México e Peru.

17 Uma explicação para esse comportamento é dada por Brock e Rojas-Suarez (2000, p. 9-10) nos seguintes termos: “(...) With the best-quality borrowers already being served by the strongest institutions, weak banks have tended to operate with low interest rate spreads for two reasons. First, poorly-capitalized banks often have the incentive to lower rates and raise deposit rates to capture greater market-share. Second, the lack of bank provisioning for loan losses causes reported spread to decline when the loan portfolio (and income) deteriorates. Because of these two reasons, the relationship between interest rate spreads and portfolio risk may differ from industrial countries." 
a taxa de câmbio. De fato, anteriormente à mudança no regime cambial, em janeiro de 1999, todo movimento mais forte de saída de capitais de curto prazo, em virtude de mudanças nas expectativas dos agentes financeiros domésticos e internacionais, ocasionava uma perda de reservas por parte do Banco Central do Brasil (BCB), ameaçando a manutenção do sistema de câmbio semifixo. Para impedir o colapso da política cambial, o BCB elevava a taxa de juros doméstica de forma a induzir uma reversão do movimento de saída de capitais. Após a mudança do regime cambial em janeiro de 1999, os movimentos de saída de capitais de curto prazo, induzidos por mudanças nas expectativas dos agentes financeiros, passaram a refletir não somente perda de reservas internacionais e elevação da taxa de juros, mas também sobre a própria a taxa de câmbio. Mais especificamente, os movimentos de saída de capitais de curto prazo induziam (e podem induzir) uma grande desvalorização da taxa nominal de câmbio, a qual, se repassada para os preços domésticos - por intermédio do assim chamado efeito pass through, - poderia provocar efeitos deletérios sobre a trajetória da inflação e sobre o estado de ânimo dos empresários. Dessa forma, o BCB tem fundamentalmente utilizado a taxa de juros para reverter o fluxo de saída de capitais e impedir assim o aumento da inflação devido à desvalorização do câmbio, acabando por afetar tanto o crescimento econômico quanto o volume da dívida pública relativa ao PIB. Neste contexto, a política monetária fica "prisioneira" do objetivo único de estabilidade de preços, tendo ao mesmo tempo efeitos macroeconômicos desestabilizadores sobre a economia brasileira (em termos do nível do produto e emprego). ${ }^{18}$

Como veremos na seção 5, a oscilação da taxa de juros é um dos fatores macroeconômicos fundamentais na explicação do spread bancário. De fato, neste contexto de instabilidade macroeconômica, os bancos têm procurado - em razão de sua maior aversão ao risco típica de um contexto de maior instabilidade macroeconômica - compensar o maior risco percebido (em termos do risco de default dos empréstimos e do risco de taxa de juros) aumentando o spread bancário, de modo a elevar suas margens líquidas de lucro.

\subsection{Evolução do spread no período recente}

O spread nas operações bancárias é definido como a diferença entre a taxa de aplicação nas operações de empréstimo e a taxa de captação de recursos pelas instituições financeiras. ${ }^{19}$ As taxas de juros cobradas no Brasil apresentam-se como as mais elevadas do mundo, segundo dados do FMI. Na Figura 1 constatamos que o spread médio dos empréstimos para pessoas físicas e jurídicas praticados no sistema bancário brasileiro, em 1994, era de cerca de $120 \%$, um valor aproximadamente oito vezes maior do que o país que possuía a segunda maior taxa cobrada, dentre os selecionados. ${ }^{20}$ Passados os primeiros anos de implantação do Plano Real, o spread cobrado pelas instituições financeiras do País continuam elevados, cerca de 55\% em 1999, embora aqui tenha reduzido a diferença com relação aos demais países. Em 2003, o spread médio no Brasil foi de 44\%, uma taxa aproximadamente três vezes maior se comparada à dos países latino-americanos e dez vezes maior do que a taxa cobrada nos países do leste asiático.

18 Para uma análise dos impasses atuais da economia brasileira, ver Oreiro et al. (2003).

19 Ao tratarmos de spreads bancários no Brasil, estamos adotando a mesma definição do Banco Central segundo o qual "o spread bancário é definido como sendo a diferença entre a taxa de empréstimo e a taxa de captação de CDB [certificado de depósito bancário]. A taxa média de CDB para o conjunto das instituiçóes financeiras foi calculada a partir de uma média das taxas individuais ponderada pela captação líquida de cada instituição." (Banco Central do Brasil, 2002, p. 50).

20 Deve ser ressalvado que os dados do FMI, calculados de forma tradicional com base no spread médio (diferença entre taxa de empréstimos e taxa paga sobre depósitos), são fortemente contaminados pelo nível da taxa de juros observada em cada país e não consideram duas dimensões importantes: a natureza e a abrangência das operações utilizadas para o cálculo do spread e o segmento de tomadores utilizados para apurar a taxa de juros de empréstimo. Por isso, os dados relativos ao Brasil estão sobredimensionados comparativamente a outros países. Uma alternativa, para efeito de comparação internacional, é adotar o índice de Lerner. Ver, a esse respeito, o artigo de Nakane e Costa (2005). Em que pese esse sobredimensionamento, não resta dúvida que o spread bancário no Brasil é um dos mais elevados do mundo, mesmo se incluirmos na amostragem os países emergentes. 
Figura 1 - Spread bancário no Brasil e no mundo

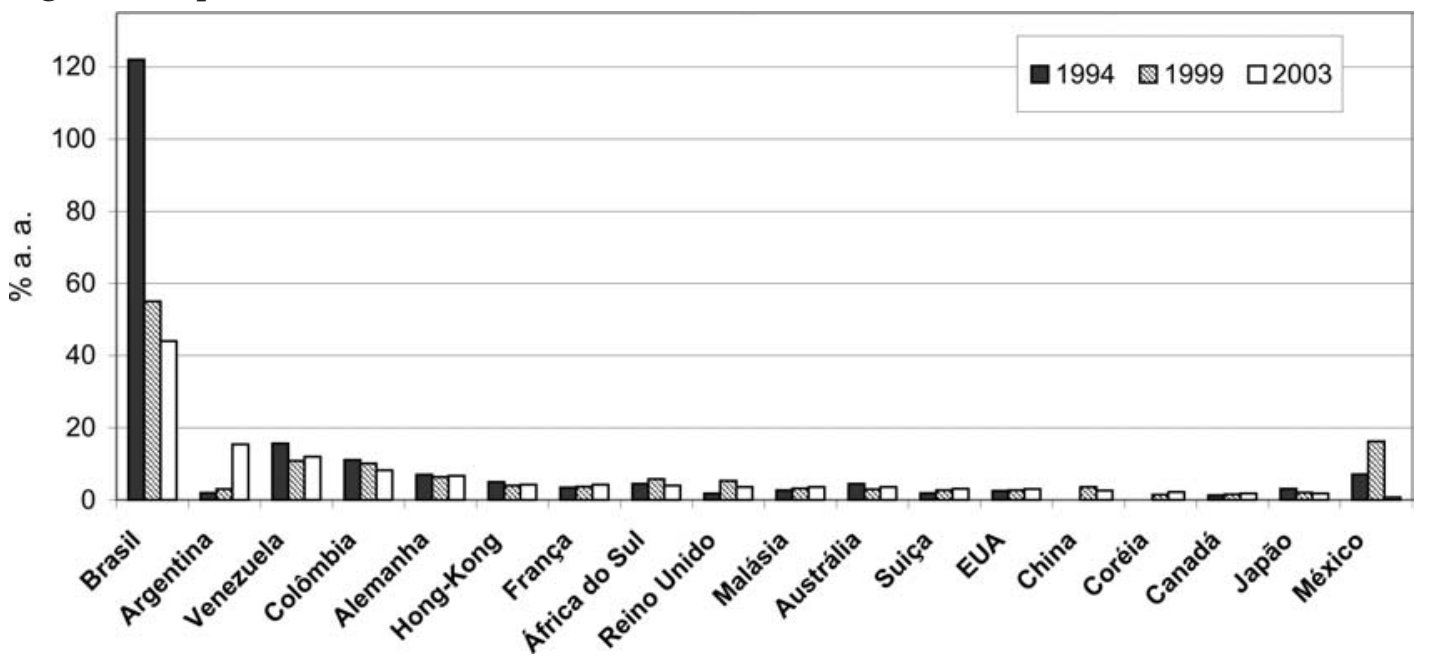

Fonte: IEDI, Carta n. 100, 2004, a partir de dados do FMI e do BCB.

Uma segunda observação importante sobre o comportamento do spread bancário no Brasil é que o mesmo apresentou uma nítida tendência de queda até início do ano 2000. Conforme pode ser visualizado na Figura 2 abaixo, o spread médio cobrado pelos bancos brasileiros alcançou um valor máximo de $150 \%$ ao ano no início de 1995 , em razão das medidas de política monetária fortemente contracionistas implementadas pelo BCB no período após a implementação do Plano Real, ${ }^{21}$ reduzindo de forma significativa no decorrer de 1996, em virtude de um relaxamento das medidas de arrocho monetário e uma diminuição da desconfiança dos agentes em relação ao processo de contágio da crise mexicana, até atingir o patamar de aproximadamente $40 \%$ ao ano no início de 2000. Cabe ressaltar que ele se manteve nesses patamares - ainda elevadíssimos - desde então, inclusive com uma leve tendência ascendente a partir de meados de 2001.

Analisando a trajetória do spread bancário após o Plano Real, Oliveira (2004, p. 69) resume as características principais desta trajetória: "1) os spreads bancários caíram vertiginosamente desde a implantação do Plano Real, porém ainda permanecem em níveis muito elevados; 2) os recolhimentos compulsórios sobre as operações ativas dos bancos no período logo após o Plano Real foram determinantes para os elevadíssimos níveis alcançados pelos spreads bancários logo após o Plano Real; 3) em geral, os spreads cobrados nas operações com pessoas físicas são bem superiores aos praticados com empresas; 4) as margens cobradas pelos bancos em suas operações de empréstimos são bastantes suscetíveis a mudanças do cenário macroeconômico, sejam elas provenientes de choques externos ou domésticos; e 5) descontada a trajetória do spread antes de outubro de 1999, a queda observada mostra-se bem menos pronunciada, mas ainda assim significativa."

21 Além da política de juros reais positivos, essas medidas incluíram inicialmente o estabelecimento de um compulsório de $100 \%$ sobre depósitos a vista, e a partir de dezembro de 1994, 30\% sobre depósitos a prazo e de $15 \%$ sobre qualquer operação de crédito. 
Figura 2 - Evolução do spread bancário brasileiro (1994-2003)

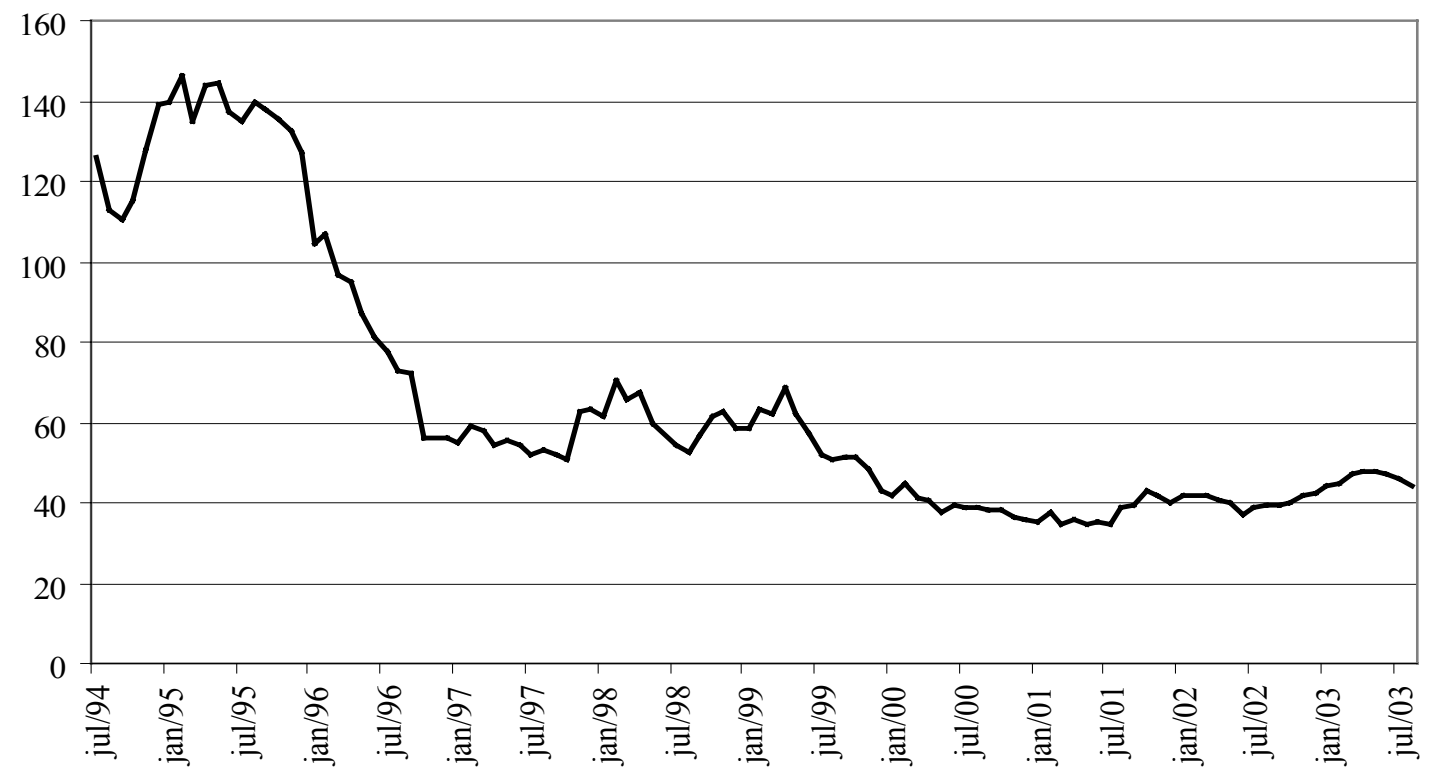

Fonte: Banco Central do Brasil.

Apesar do grande tamanho do sistema bancário brasileiro (veja a coluna ativos/PIB na Tabela 1) em comparação com outros países latino-americanos, os empréstimos bancários em proporção do PIB são muito modestos, especialmente quando confrontados com países desenvolvidos.

Tabela 1 - Sistema financeiro em alguns países selecionados - 2000 (\% do PIB)

\begin{tabular}{lcccc}
\hline & \multicolumn{3}{c}{ Setor bancário (1) } & \multirow{2}{*}{$\begin{array}{c}\text { Capitalização no } \\
\text { mercado acionário }\end{array}$} \\
\cline { 2 - 4 } País & Depósitos & Empréstimos & Ativos n & \\
\hline Brasil & 29,3 & $24,8(2)$ & 77,1 & 35,0 \\
Argentina & 27,8 & 21,4 & 57,4 & 58,2 \\
Mexico & 18,3 & 21,6 & 25,0 & 22,1 \\
Chile & 54,9 & 70,0 & 98,4 & 86,4 \\
EUA & 42,6 & 45,3 & 77,3 & 152,0 \\
Japão (3) & 94,8 & 84,7 & 142,0 & 68,0 \\
Zona do Euro & 78,9 & 103,7 & 258,3 & 89,0 \\
\hline
\end{tabular}

(1) Somente bancos deposítários.

(2) Dado inclui operações de leasing comercial.

Fonte: Belaisch (2003, p. 4).

Com o sucesso do Plano Real no que se refere à estabilização de preços, poder-se-ia esperar um aumento substancial dos empréstimos como proporção do PIB, já que baixas taxas de inflação 
sinalizariam um ambiente macroeconômico mais estável. Contudo, isto não ocorreu. Na verdade, houve uma redução do crédito como proporção do $\mathrm{PIB}^{22}$ e constatou-se uma elevada volatilidade das taxas de juros nesse período, devido em grande parte aos impactos das crises financeiras internacionais em contexto de elevada vulnerabilidade externa, constituindo-se em uma fonte de instabilidade econômica. Como já assinalamos, apesar da redução em relação aos níveis de 1994, os spreads bancários permaneceram em níveis elevados nos últimos anos.

Uma primeira hipótese explicativa para o porquê dos elevados spreads praticados no Brasil seria o poder de mercado dos bancos, evidenciado pelo aumento da concentração bancária no período recente. Com efeito, alguns estudos recentes sobre o setor bancário brasileiro - como, por exemplo, Belaisch (2003) - mostram que a estrutura de mercado prevalecente nesse setor é essencialmente não-competitiva. ${ }^{23}$ Nesse contexto, os bancos teriam poucos incentivos para aumentar a sua eficiência operacional, operando com spreads elevados, quer como forma de gerar receita suficiente para cobrir os seus custos elevados, quer como resultado da capacidade de precificar os seus serviços num patamar bastante superior ao custo marginal de produção dos serviços bancários.

Um fator que daria suporte à hipótese de que o problema do spread no Brasil é resultado do poder de mercado dos bancos é a tendência recente de aumento da concentração do setor bancário. Com efeito, no período 1988-2003 o market share dos 15 maiores bancos privados no ativo total do sistema bancário aumentou de cerca de $29 \%$, em junho de 1988, para aproximadamente 47\%, em janeiro de 2003 (cf. Figura 3).

Figura 3 - Participação dos 15 maiores bancos privados no ativo total do sistema bancário (19882003)

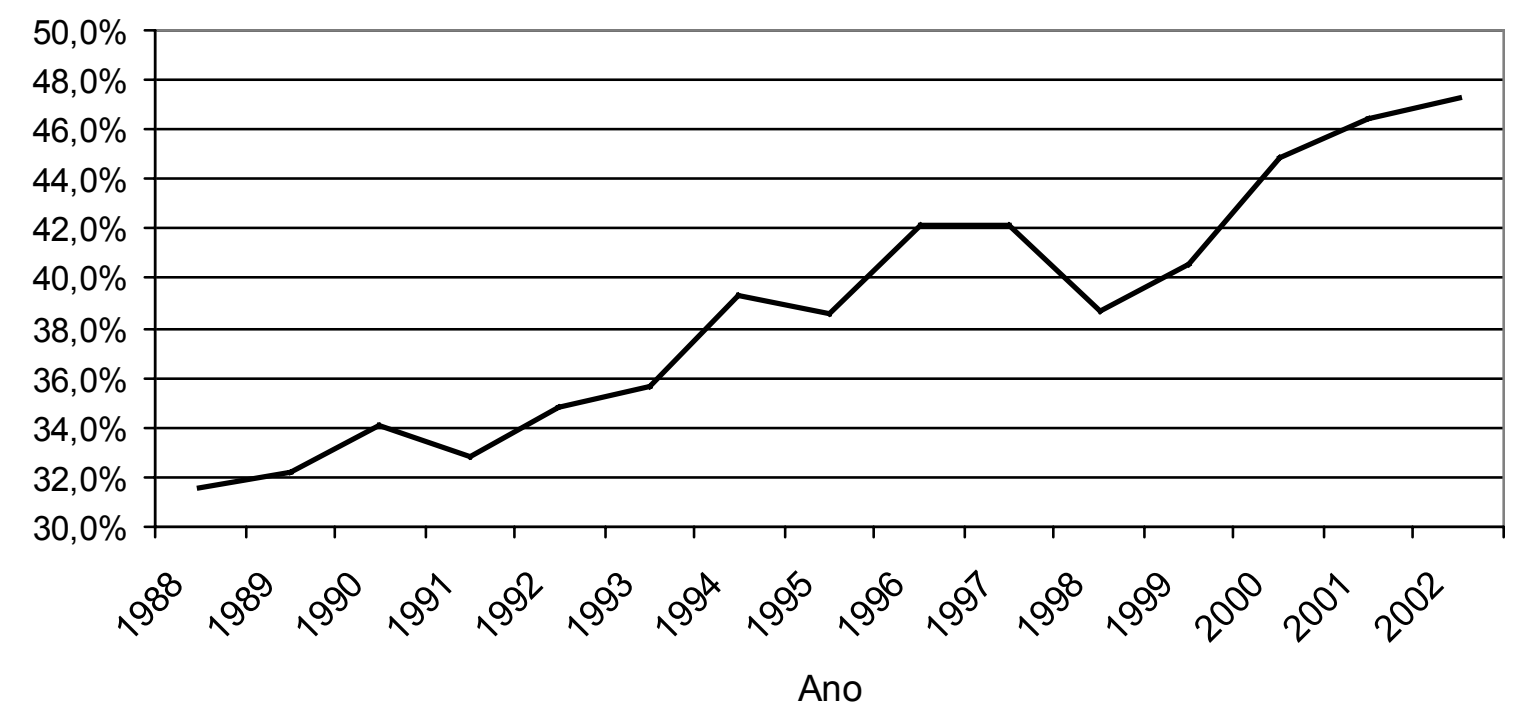

Fonte: Coutinho (2003, p. 20).

22 Conforme dados do Banco Central do Brasil, a relação crédito total/PIB, que era de 40\% em junho de 1995, passou a ser menor do que $30 \%$ em praticamente todo o período 2000/03.

23 Nakane (2002), usando séries temporais agregadas durante o período 1994-1998, encontrou evidências da existência de uma estrutura de mercado não-competitiva no setor bancário brasileiro. Entretanto, os resultados alcançados rejeitam a hipótese de que os bancos brasileiros formam um cartel. 
Uma das características mais marcantes de um sistema bancário é a presença de assimetria de informações. Um banco tem mais informação sobre as características de seus clientes do que seus concorrentes, e devido a problemas de seleção adversa torna-se muito difícil atrair clientes de boa qualidade (bons pagadores) sem que os benefícios e ofertas concedidos também atraiam clientes de baixa qualidade. A existência de custos de informação e de transferência - tanto pelos bancos, que precisam conhecer melhor seus clientes, como pelos clientes, que devem demonstrar suas qualidades para obter benefícios em outros bancos - possibilitariam aos bancos a prática do poder de mercado. Conforme sugere Nakane (2003, p. 66):

"(...) Modalidades de crédito relacionadas com a manutenção de contas bancárias,
tais como cheque especial para pessoas físicas e conta garantida para pessoas jurí-
dicas são tipicamente situações em que os clientes estão presos (locked in) a suas
instituições bancárias, pela dificuldade de transferir a instituições competidoras seu
histórico cadastral e reputação. Como resultado de elevados custos de transferência,
as taxas de juros nestas modalidades são sensivelmente mais elevadas que em mo-
dalidades representando substitutos próximos [crédito pessoal e financiamento de
capital de giro]."

Se a hipótese de poder de mercado dos bancos estiver correta, então os índices de concentração teriam que ter impacto sobre as taxas de empréstimo cobradas pelos bancos, resultando em elevados índices de rentabilidade. De fato, pelo menos no segmento varejista privado do setor bancário, as evidências poderiam sugerir que esse seria o caso, considerando que a rentabilidade média dos 3 maiores bancos privados brasileiros - Bradesco, Itaú e Unibanco - foi de 17,3\% no período 1994/2001, bem superior à média de 11,8\% de 3 grandes empresas não financeiras nacionais - Petrobrás, Votorantim e CVRD. (Málaga et al., 2003, p. 12).

A literatura brasileira que trata dos determinantes do spread bancário não tem sido conclusiva a respeito do assunto. Os estudos realizados apresentam evidências de que a estrutura de mercado do setor bancário brasileira é imperfeita, mas não caracterizando a existência de cartel. Com efeito, a revisão da literatura empírica, referente ao caso brasileiro, feita por Nakane (2003), aponta para as seguintes conclusões: (i) a concentração do setor bancário brasileiro, medida pelo índice de Herfindahl, não é elevada em comparação com a prevalecente em outros países; (ii) os índices de concentração de mercado não têm um impacto estatisticamente significativo sobre as taxas de juros cobradas pelos bancos; (iii) a estrutura de mercado do setor bancário não é representada por nenhuma das estruturas de mercado extremas (concorrência perfeita e cartel) e, portanto, se caracteriza como uma estrutura imperfeita. ${ }^{24}$

\subsection{Estudos empíricos sobre spread bancário no Brasil}

Um dos estudos pioneiros sobre os determinantes do spread bancário no Brasil foi feito por Aronovich (1994). Este autor verificou, por meio de uma regressão por mínimos quadrados em dois estágios, os efeitos da inflação e do nível de atividade sobre o spread para a economia brasileira entre o primeiro trimestre de 1986 e o quarto trimestre de 1992. Os resultados encontrados indicam que a inflação tende a ampliar a diferença entre as taxas de juros de empréstimo e de captação, ou seja, o spread. O autor sugere como causas desse fenômeno a possibilidade de uma redistribuição entre as operações do ativo, ou ainda a incorporação ao mark up do prêmio de risco envolvido no

24 Cabe destacar que "in principle (...), there is no one-to-one relationship between market concentration and the degree of competition [in banking market]" e que "some of the same forces promoting consolidation in emerging markets, such as increased foreign bank entry, are also likely to foster competition.” (IMF 2001, p. 158). 
crédito. Neste sentido, a inflação teria um efeito negativo sobre o nível de atividade ao induzir um aumento das taxas de juros para empréstimos bancários. Por outro lado, os testes estatísticos sugerem que um aumento da utilização de capacidade produtiva reduziria o spread, indicando assim um efeito pró-cíclico.

Em um outro estudo realizado por Afanasieff et al. (2002) foram identificados dois fatos estilizados sobre o comportamento dos spreads após o Plano Real, a saber: (a) a queda pronunciada das taxas de juros após $1995^{25}$; (b) uma dispersão elevada e persistente entre as taxas de empréstimos praticadas pelos bancos. Estes fatos justificaram a utilização da metodologia primeiramente empregada por Ho e Saunders (1981) para a determinação dos spreads bancários. Em um primeiro passo, utilizou-se um painel de dados para 142 bancos comerciais entre fevereiro de 1997 e novembro de 2000 , de forma a captar a influência individual (por banco) de variáveis microeconômicas ${ }^{26}$ sobre o spread, ou seja, aquelas relacionadas às características específicas dos bancos. A partir desse painel, foi possível obter uma estimativa do spread puro (ver seções 2 e 3 do presente artigo). Numa segunda etapa, estimou-se, por meio de um modelo estrutural, a influência de longo prazo de variáveis macroeconômicas (taxa de juros de mercado, uma medida de prêmio de risco: spread do C-bond sobre um título do Tesouro dos EUA com a mesma maturidade, taxa de inflação, taxa de crescimento do produto, depósito compulsório sobre depósitos a vista e taxa de imposto financeiro - i.e., IOF, PIS-COFINS e CPMF) sobre o spread puro calculado anteriormente.

Os resultados das regressões no primeiro passo mostram que as seguintes variáveis apresentam significância estatística: razão entre os depósitos que não rendem juros e os ativos totais, custos operacionais, razão entre receita de serviços e receitas operacionais totais - tendo todas essas variáveis um efeito positivo sobre spread bancário -, além de uma dummy para os bancos estrangeiros, cujo resultado negativo indica que esses bancos cobram spreads menores, em média.

Os coeficientes estimados no segundo passo foram significativos, sugerindo a relevância dos aspectos macroeconômicos como principais determinantes dos spreads no Brasil. Os resultados da regressão sugerem que o spread tende a aumentar com a elevação da taxa básica de juros, do prêmio de risco, do crescimento do produto e dos impostos. Ao contrário do esperado, a taxa de inflação afeta negativamente o spread, possivelmente devido a fato de que inflação possa estar capturando o efeito da apropriação da senhoriagem do banco sobre o spread.

Um outro estudo importante sobre os determinantes do spread bancário no Brasil tem sido conduzido pelo Banco Central no contexto do projeto "Juros e spread bancário". ${ }^{27}$ Nesse estudo, publicado na forma de relatórios anuais a partir de 1999, é feita uma decomposição contábil do

25 O ambiente internacional mais estável, a queda na taxa de overnight e medidas adotadas pelo Banco Central contribuíram para a redução dos spreads. (Paula e Alves Jr., 2003, p. 358). Em relação a estas últimas, devemos destacar a redução do compulsório sobre depósitos a vista de $75 \%$ para $45 \%$ e dos depósitos a prazo de $20 \%$ para $0 \%$, novas regras para a provisionamento de créditos de liquidação duvidosa, redução da alíquota do IOF de $6 \%$ para 1,5\% e o desenvolvimento da central de risco de crédito.

26 As variáveis selecionadas por Afanasieff et al. (2002) foram: (a) número de agências bancárias; (b) razão entre os depósitos que não rendem juros e os ativos operacionais totais; (c) razão entre os ativos que rendem juros e os ativos totais; (d) custos operacionais; (e) liquidez do banco; (f) razão entre a receita de serviços e as receitas operacionais totais; (g) valor líquido do banco; e (h) alavancagem do banco.

27 Ver, entre outros, Banco Central do Brasil (1999; 2002; 2004). 
spread, ${ }^{28}$ além de outros estudos econométricos sobre os determinantes do spread no Brasil. O spread bancário no Brasil é decomposto a partir das margens cobradas pelos bancos contemplados em uma amostra ${ }^{29}$ referida em suas operações de créditos livres contratadas apenas sob taxas de juros prefixadas. São considerados os seguintes componentes: (a) resíduo, que corresponde, grosso modo, à margem líquida do banco; (b) cunha tributária, que inclui impostos diretos (IR e CSLL) e impostos indiretos (PIS, COFINS e IOF); (c) Fundo Garantidor de Crédito (FGC); (d) custo administrativo; e (e) inadimplência (despesas de provisão).

A Figura 4 apresenta a participação de cada um desses componentes no spread praticado pelos bancos no Brasil, entre 2000 e 2003, já levando em conta a metodologia revista em 2004. ${ }^{30}$ Com base na decomposição contábil do spread, os fatores mais importantes na formação do mesmo são, respectivamente, o resíduo (26,9\% em média em 2000/2003) e custo administrativo (26,0\%), seguidos da cunha tributária $(21,6 \%)$ e inadimplência $(19,9 \%)$. Os compulsórios (o item de menor peso na decomposição contábil) passaram a apresentar um peso relativamente maior em 2002 (9,1\% do spread), em virtude da imposição de exigibilidades adicionais de recolhimentos compulsórios nesse ano.

Para a decomposição econométrica do spread supõe-se a validade da seguinte equação estrutural:

$\ln$ spread $=\beta_{0}$ Trend $+\beta_{1} \ln$ selic $+\beta_{2} \ln a d m+\beta_{3} \ln$ risk $+\beta_{4} \ln i m p+\beta_{5} \ln$ comp

Em que $\beta_{i i}(i=0, \ldots, 5)$ são os parâmetros estimados; o Trend é uma tendência determinista que controla outras variáveis que podem ter efeito sobre spread, mas que não estão apresentados na equação acima. ${ }^{31}$ Os regressores são a Selic, que é a taxa básica de juros; $a d m$ é uma medida da despesa administrativa dos bancos; risk é uma proxy para o risco de crédito, medido através do spread do C-Bond sobre o rendimento dos títulos do Tesouro Americano de mesma maturidade; imp são impostos indiretos; e o comp é o porcentual de encaixes compulsórios sobre os depósitos a vista dos bancos.

28 A decomposição contábil do spread pode ser feita por intermédio de identidades contábeis simples como as que apresentaremos a seguir (cf. Demirgüç-Kunt e Huizinga, 1999, p. 381). Defina-se a margem líquida de intermediação dos bancos (NIM) como a razão entre o valor contábil da renda de juros e o valor dos ativos do banco. Seja BTA o lucro antes dos impostos, ATP o lucro após os impostos, TA o valor dos ativos do banco, e TX o montante de imposto pago pelo banco. Temos que: $\frac{B T A}{T A} \equiv \frac{A T P}{T A}+\frac{T X}{T A}$. Seja OV os custos administrativos do banco, LLP a provisão para empréstimos de liquidação duvidosa e NII a receita extra-juros do banco. A rentabilidade como proporção do ativo do banco pós-impostos pode ser expressa por: $\frac{B T A}{T A} \equiv N I M+\frac{N I I}{T A}-\frac{O V}{T A}-\frac{L L P}{T A}$. Daqui se segue que a margem líquida de intermediação do banco (NIM) pode ser expressa por: $N I M=\frac{A T P}{T A}+\frac{T X}{T A}-\frac{N I I}{T A}-\frac{O V}{T A}-\frac{L L P}{T A}$. Dessa forma, a margem líquida de intermediação pode ser calculada residualmente, uma vez que se conheça os valores da rentabilidade (pré-impostos) como proporção do ativo do banco, os impostos pagos como proporção do ativo, a receita extra-juros como proporção do ativo, os custos operacionais como proporção do ativo e a provisão para empréstimos de liquidação duvidosa como proporção do ativo do banco. Nesse contexto, a decomposição contábil do spread nada mais é do que um cálculo simples da participação em termos porcentuais de cada um desses fatores na formação da margem líquida de intermediação.

29 Os dados eram calculados até 2003 a partir de informações coletadas nos demonstrativos mensais de dezessete grandes bancos privados que operam no País; a partir de 2004, ampliou-se a amostra utilizada, trabalhando-se com um universo de bancos - comerciais, múltiplos, CEF e Banco do Brasil - que engloba todos os bancos atuantes no País em cada data-base e para os quais as informações necessárias estão disponíveis.

30 Na Figura 4 o "Custo do FGC" é somado à "Cunha Tributária", por ter valores abaixo de 0,30\%. A metodologia revista em 2004, além de ampliar a mostra de bancos utilizada na pesquisa, estabelece uma nova forma de calcular o custo administrativo, fugindo da hipótese de alocação de custos com base em geração de receita, como era feita anteriormente, utilizando para tanto o cálculo de preços de Aumann-Shapley. Ver, a respeito, Banco Central do Brasil (2004, cap. III).

31 Tais como a taxa de inflação, o nível de atividade econômica, as mudanças estruturais na indústria bancária decorrente das políticas de juros, a entrada de bancos etc. 
Figura 4 - Descomposição do spread no Brasil

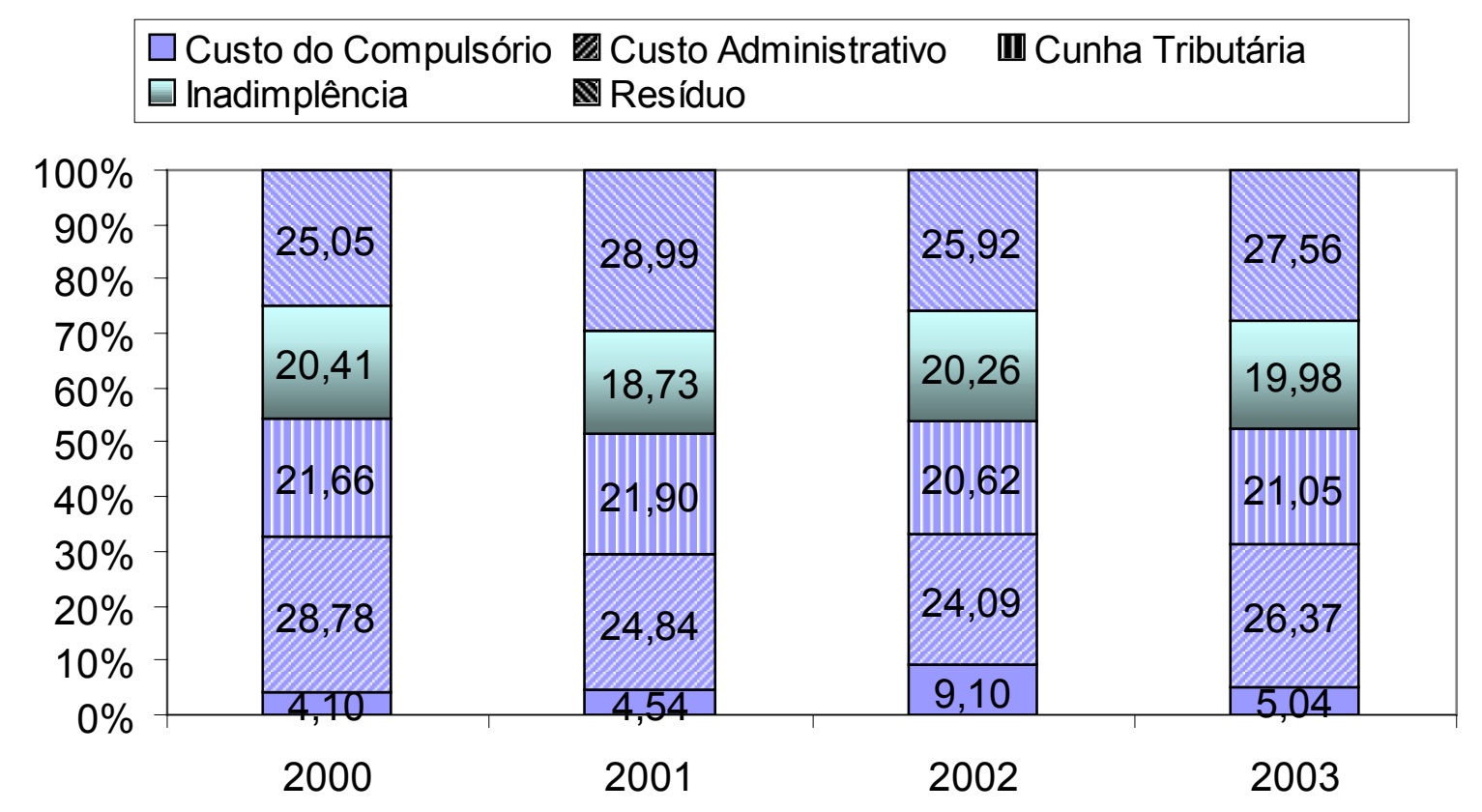

Fonte: Banco Central do Brasil (2004, p. 11).

Foram feitas oito defasagens em todas as variáveis da estimação, incluindo variáveis dummies para janeiro de 1996, novembro de 1997 e dezembro de 1997 de forma a gerar resíduos normais. Isso posto, a equação estimada pelo Banco Central foi a seguinte:

In spread $=-0,0003$ trend $+0,503 \ln$ Selic $+1,554 \ln$ adm $+0,219 \ln$ risk $+0,723 \ln$ imp

Com base nesta equação, podemos concluir que o spread médio dos bancos brasileiros depende positivamente da taxa básica de juros, das despesas administrativas dos bancos, do risco e dos impostos.

Como as variáveis foram expressas em logaritmo natural, segue-se que os coeficientes da equação estimada nada mais são do que as elasticidades do spread a cada uma dessas variáveis. Neste contexto, o que mais chama a atenção no estudo do Banco Central é a elevada sensibilidade do spread bancário a variações nas despesas administrativas dos bancos. De fato, com base na equação estimada pelo Banco Central uma redução de $1,0 \%$ nas despesas administrativas dos bancos geraria uma redução de $1,55 \%$ no spread médio cobrado pelos bancos. Ademais, vale destacar a crescente participação dos lucros dos bancos na composição dos spreads.

A partir da metodologia adotada pelo Banco Central para a decomposição do spread, Koyama e Nakane (2001) analisam o impacto esperado sobre o spread de alguma alteração em seus componentes, quais sejam: despesas administrativas, despesas de inadimplência, impostos indiretos, impostos diretos e margem líquida do banco. Com o intuito de estimar um vetor auto-regressivo, os autores desagregam o spread bancário nos seguintes fatores: (i) taxa básica de juros (taxa Selic overnight), que é utilizada como uma aproximação do mark up bruto dos bancos, uma vez que os depósitos a prazo e as taxas no overnight apresentam um comportamento similar; (ii) uma medida do prêmio de risco País (o retorno dos títulos C-Bonds em relação ao retorno de títulos do Tesouro 
americano com o mesmo prazo de maturidade); (iii) a razão das despesas administrativas sobre o volume de crédito; e (iv) impostos indiretos (IOF, PIS, COFINS e CPMF).

Os autores testaram a existência de co-integração entre as variáveis e encontraram as seguintes importâncias relativas para setembro de 2001: componente de risco (45\%), despesas administrativas (20\%), impostos indiretos (19\%) e taxa Selic overnight (16\%). Nessa análise dos spreads bancários, a participação das variáveis de relativas ao risco foi maior do que a participação das despesas com inadimplência, conforme o estudo rotineiramente realizado pelo Banco Central. Isso pode ser explicado pela característica expectante (forward looking) das variáveis de risco com respeito a cenários futuros, enquanto as despesas com inadimplência têm um caráter retrospectivo, referente a perdas passadas. Deste modo, uma vez que 2001 foi um ano marcado pela incerteza na economia brasileira, a importância do componente de risco sobre o spread previsivelmente elevou-se. Já a importância da taxa Selic na determinação do spread pode ser compreendida diferentemente. Uma vez que os títulos do governo são a priori livres de risco, então a taxa básica de juros determina um custo de oportunidade em relação a empréstimos ao setor privado (cf. Paula e Alves Jr., 2003, p. 361).

\section{OS DETERMINANTES MACROECONÔMICOS DO SPREAD NO BRASIL: 1995/2003}

Nesta seção realiza-se uma análise de regressão múltipla com o intuito de identificar as variáveis macroeconômicas que podem estar influenciando direta e/ou indiretamente o spread bancário no Brasil no período janeiro de 1995 a dezembro de 2003.

Para o exercício econométrico incorporaram-se as seguintes variáveis ao modelo: Spread, volatilidade da taxa de juros (proxy de risco de taxa de juros do banco), taxa de juros Selic, produto industrial e IPCA (Índice Nacional de Preços ao Consumidor-Amplo). A escolha dessas variáveis baseou-se inicialmente no trabalho de Afanasieff et al. (2002), no qual, como visto, conclui-se que as variáveis macroeconômicas são mais relevantes do que as microeconômicas na determinação do spread no Brasil.

Como visto na seção 2, espera-se que quanto maior (menor) a taxa de inflação, o nível e a volatilidade da taxa de juros, ao aumentarem (diminuírem) o risco de taxa de juros e o risco de crédito dos bancos, maior (menor) deverá ser o nível do spread bancário. ${ }^{32}$ Já o efeito da atividade econômica sobre o spread tende a ser dúbio, pois se por um lado um maior ritmo da atividade econômica tende a ter um efeito benéfico sobre o spread, ao diminuir o nível da inadimplência e aumentar a escala de operação na concessão de crédito bancário, com efeitos benéficos sobre os custos destes, por outro lado, uma maior demanda por crédito tende a resultar em maiores taxas de empréstimos, dependendo, contudo, do poder de mercado dos bancos líderes. É provável que cada um desses efeitos predomine em determinado momento. Por fim, o nível do compulsório, variável regulatória sob o controle do Banco Central, tem impacto de sinal positivo sobre o spread, uma vez que a sua elevação impacta diretamente a magnitude do multiplicador bancário.

Para efeito do exercício econométrico feito neste artigo, foram coletados dados mensais para:

- Spread bancário, segundo o banco central (definido como a série 3955 - spread médio das operações de crédito com recursos livres 'prefixado' - total geral);

- Índice de produção industrial do IBGE, utilizado como proxy para o nível de atividade econômica (definido como a Tabela 2295 do IBGE: Produção Física Industrial por tipo de índice e seções e atividades industriais);

32 Outro efeito mais direto do nível da taxa de juros sobre o spread está relacionado à existência de uma forte correlação positiva entre a taxa de juros básica e a taxa de empréstimos bancários, devido ao mark up bancário mais ou menos fixo a curto prazo. 
- Taxa de juros SELIC do Banco Central (definida como a série 4189: taxa de juros Selic acumulada no mês, anualizada);

- Taxa de inflação, medida pela variação mensal do IPCA do IBGE (definida como a série 433 do Banco Central: Índice Nacional de Preços ao Consumidor-Amplo);

- Volatilidade da taxa SELIC: trata-se da variância condicional, calculada a partir de um modelo GARCH $(1,1)$, sendo que para a equação da média da taxa SELIC utilizou-se um modelo $\operatorname{AR}(2) ;^{33}$

- Alíquota do compulsório sobre depósitos a vista: a série foi calculada pesquisando-se as circulares do Banco Central desde $1994^{34}$

A Figura 5 mostra o comportamento das variáveis selecionadas em nível no período de janeiro de 1995 a dezembro de 2003.

Figura 5-As variáveis macroeconômicas em nível
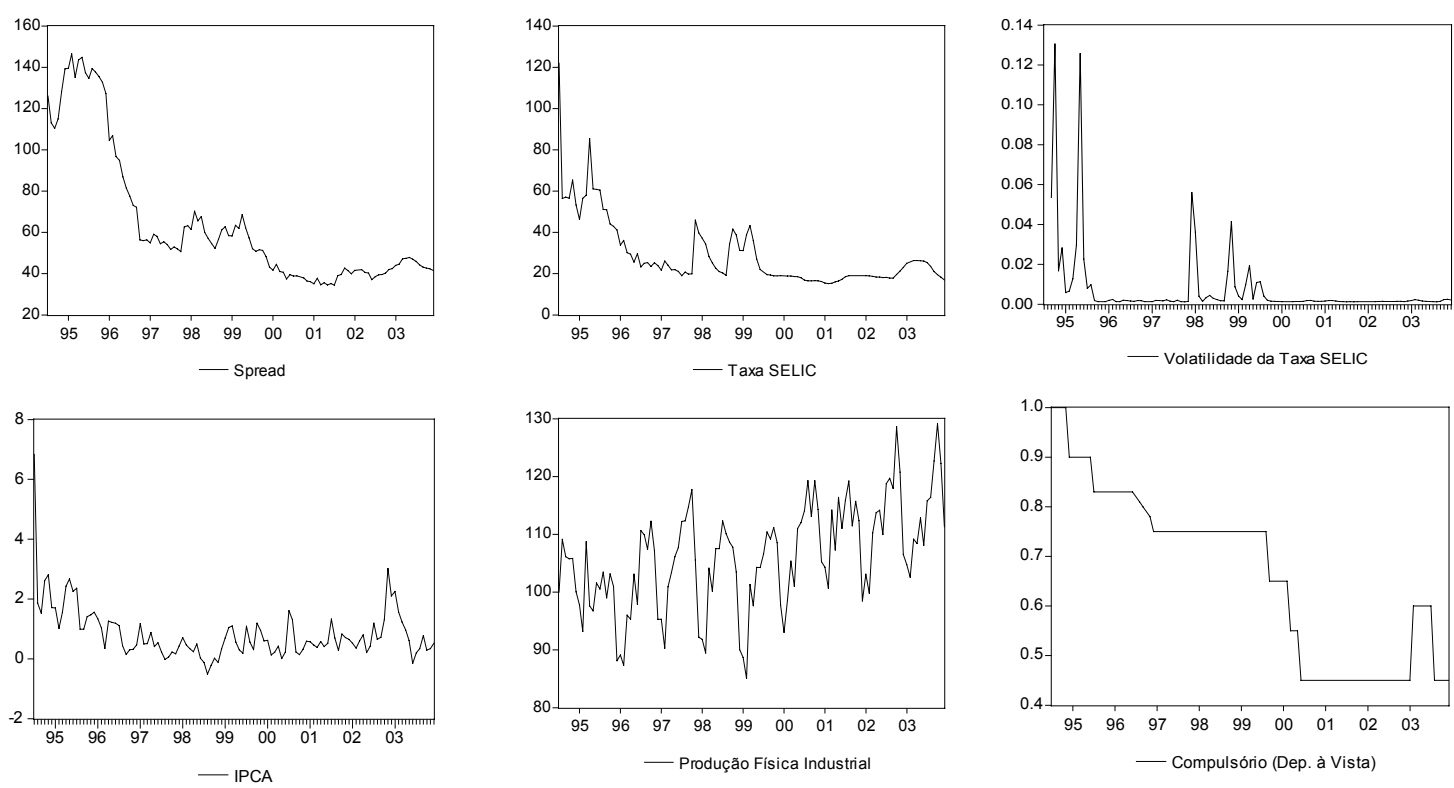

\subsection{Determinantes macroeconômicos do spread bancário: um modelo VAR}

O objetivo desse tópico é encontrar os determinantes macroeconômicos do spread bancário no Brasil. Acredita-se que spread é determinado principalmente pela produção industrial, pela taxa de inflação, pela volatilidade da taxa de juros (efeito risco), pelo nível da taxa de juros (efeito da taxa média de juros) e compulsório (variável exógena).

33 Nos casos em que a variância não é constante, utiliza-se o GARCH (Generalised Autoregressive Conditional Heteroskedastic) para modelar a volatilidade (variância condicional) ao longo do tempo. Nesse caso, utiliza-se um modelo ARMA (auto-regressivo de médias móveis) para a média (isto é, a média também varia ao longo do tempo).O correlograma da taxa Selic demonstrou que a média é melhor modelada por meio de um $\mathrm{AR}(2)$. O modelo utilizado para o cálculo da variância condicional foi: $\sigma_{t}^{2}=\omega+\alpha \varepsilon_{t-1}^{2}+\beta \sigma_{t-1}^{2}$

34 Veja as circulares 2377/93, 2423/94, 2441/94, 2521/94, 2593/95, 2603/95, 2700/96, 2927/99, 2969/2000, 2983/2000, 3002/2000, $3063 / 2000,3087 / 2002,3134 / 2002,3169 / 2002,3177 / 2003$ e 3199/2003. 
O primeiro passo do exercício foi verificar a ordem de integração das séries econômicas por meio do teste de Augmented Dickey-Fuller (ADF) com intuito de detectar ou não a estacionariedade das séries. O teste sinalizou que todas as variáveis endógenas são estacionárias a $5 \%$ de significância, exceto o spread, que foi estacionário a 10\%. Os resultados estão apresentados na Tabela 2:

Tabela 2 - Teste de raiz unitária (Augmented Dickey-Fuller Test - ADF)

\begin{tabular}{lcccccc}
\hline Discriminação & Defasagens & Constante & Tendência & DW & ADF & Valor Crítico 5\% \\
\hline SPREAD & 0 & Sim & Não & 2.164855 & $-2.878739^{* * *}$ & -2.888669 \\
SELIC & 2 & Sim & Não & 1.801741 & $-2.900228^{* *}$ & -2.889200 \\
VOLSELIC & 0 & Sim & Não & 1.972421 & $-7.299358^{*}$ & -2.888669 \\
PRODFIS1 & 3 & Sim & Sim & 1.985376 & $-6.289157^{*}$ & -3.453601 \\
IPCA & 0 & Sim & Não & 1.928283 & $-4.244377^{*}$ & -2.888669 \\
COMPULS & 0 & Sim & Não & 2,016785 & -1.166072 & -2.888669 \\
\hline
\end{tabular}

Fonte: Elaboração própria a partir da saída do Eviews 5.

Nota: *Significativo a $1 \% ; *$ Significativo a 5\%;***Significativo a $10 \%$. Os valores críticos para a rejeição da hipótese nula de raiz unitária foram gerados do pacote econométrico Eviews 5.

A hipótese básica do modelo VAR, segundo Sims (1980), o criador do método, é que as séries devem ser estacionárias, mas geralmente as séries macroeconômicas não são. Com efeito, para decidir a melhor especificação desse modelo seguiu-se a recomendação de Sims, optando-se por não diferenciar a série, ainda que a série de spread tenha sido estacionária apenas ao nível de $10 \%$. A justificativa para a estimação com todas as variáveis em nível, segundo Sims, é o fato de o objetivo dessa metodologia determinar as relações existentes entre as variáveis e não os parâmetros estimados. Contudo, os resultados do VAR estimado encontram-se no apêndice.

Para selecionar o modelo, toma-se como base os Critérios de Informação de Akaike (AIC), de Schwarz (CS) e de Hannan-Quinn (HQ). Essas estatísticas são úteis para determinar o número de defasagens a incluir no VAR. Conforme mostra a Tabela 3, apesar dos critérios de SC e HQ indicarem que o VAR ótimo é aquele com uma defasagem, decidiu-se trabalhar com 2 defasagens, tal como indicado pelo critério de AIC. ${ }^{35}$

Tabela 3 - Critério de seleção de defasagem do VAR

\begin{tabular}{lccc}
\hline Discriminação & $\begin{array}{c}\text { Critério de Informação de } \\
\text { Akaike (AIC) }\end{array}$ & $\begin{array}{c}\text { Critério de Informação } \\
\text { de Schwarz (SC) }\end{array}$ & $\begin{array}{c}\text { Critério de Informação } \\
\text { de Hannan-Quinn (HQ) }\end{array}$ \\
\hline 1 defasagens & 10.61911 & $11.50905^{*}$ & $10.97965^{*}$ \\
2 defasagens & $10.58566^{*}$ & 12.11127 & 11.20373 \\
3 defasagens & 10.60163 & 12.76292 & 11.47723 \\
4 defasagens & 10.63841 & 13.43537 & 11.77154 \\
\hline
\end{tabular}

Fonte: Elaboração própria a partir da saída do Eviews 5.

Notas: As variáveis utilizadas foram: Spread, Volatilidade da Selic, Taxa de Juros - SELIC, Produto Industrial e IPCA. A amostra corresponde a jan/1995 - dez/2003.

35 A análise do número de defasagens baseou-se nos critérios de informação e na análise da ausência de correlação serial dos resíduos. Quanto ao Teste de Normalidade dos Resíduos, o teste de Jarque-Bera rejeitou a hipótese nula de que os resíduos são normais. Contudo, dada a impossibilidade de aumentar a amostra dos dados no Brasil, e sabendo-se dos problemas que a não normalidade dos erros trazem para a análise, decidiu-se por desconsiderar tal hipótese e continuar o trabalho. Esta é uma prática utilizada em alguns trabalhos no Brasil. (Grôppo, 2004; Camuri, 2005). 
Com intuito de evitar arbitrariedade na ordenação das variáveis, utilizou-se o Teste de Causalidade de Granger (Block Exogeneity Wald Tests) para definir um ordenamento estatisticamente consistente. Este teste calcula a significância conjunta de cada variável endógena defasada para cada equação do VAR. ${ }^{36}$ Os resultados são apresentados na Tabela 4.

Tabela 4 - VEC Granger Causality/Block Exogeneity Wald Tests

\begin{tabular}{|c|c|c|c|c|c|c|c|c|c|c|}
\hline \multicolumn{11}{|c|}{ Variável Dependente } \\
\hline & \multicolumn{2}{|c|}{ IPCA } & \multicolumn{2}{|c|}{ Prodfis } & \multicolumn{2}{|c|}{ Volatil } & \multicolumn{2}{|c|}{ Selicanual } & \multicolumn{2}{|c|}{ Spread } \\
\hline & Chi-sq & Prob & Chi-sq & Prob & Chi-sq & Prob & Chi-sq & Prob & Chi-sq & Prob \\
\hline IPCA & - & - & 0.75 & 0.68 & 4.51 & 0.10 & 1.72 & 0.42 & 0.49 & 0.78 \\
\hline Prodfis1 & 3.26 & 0.19 & - & - & 1.26 & 0.53 & 6.89 & 0.03 & 4.24 & 0.11 \\
\hline Volatil & 0.15 & 0.92 & 1.78 & 0.40 & - & - & 3.23 & 0.19 & 6.00 & 0.04 \\
\hline Selicanual & 0.29 & 0.86 & 2.17 & 0.33 & 5.76 & 0.05 & - & - & 14.19 & 0.00 \\
\hline Spread & 1.40 & 0.49 & 1.58 & 0.45 & 2.93 & 0.23 & 5.73 & 0.05 & - & - \\
\hline Total & 9.639 & 0.29 & 16.50 & 0.03 & 17.03 & 0.02 & 18.38 & 0.01 & 28.61 & 0.00 \\
\hline
\end{tabular}

Fonte: Elaboração própria a partir da saída do Eviews 5.

A partir da estatística Qui-Quadrado, ordenam-se as variáveis das mais exógenas (menores valores da estatística) para as mais endógenas. De acordo com este critério, a ordenação correta é a seguinte: IPCA, Produto Industrial, Volatilidade da Selic, Taxa de Juros - SELIC e Spread. Isto implica dizer que a variável de interesse neste estudo é a mais endógena, portanto, responde contemporaneamente a todas as outras variáveis no mesmo período em que ocorrem os choques.

Em virtude da dificuldade de interpretar os coeficientes estimados para o modelo VAR é comum sumariar os resultados por meio da função de impulso-resposta e da decomposição da variância. Devido à freqüência mensal dos dados é utilizado para as análises um período de 12 meses após a ocorrência dos choques. ${ }^{37}$

As funções impulso-resposta para uma alteração de um desvio padrão estão representadas na Figura 6. Segundo Enders (1995), as funções impulso-resposta mostram os efeitos de longo prazo das séries temporais quando há um determinado choque exógeno em alguma das variáveis do modelo. Portanto, as funções-resposta ao impulso apontam a reação do spread bancário quando há algum choque exógeno nas variáveis incorporadas no modelo.

As linhas contínuas representam as funções impulso-resposta, enquanto as linhas pontilhadas representam os intervalos de confiança de dois desvios padrão, obtidos a partir de uma simulação de Monte Carlo com 1000 repetições. Os resultados apresentados nas funções impulso-resposta das variáveis em consideração ressaltam a importância da volatilidade da taxa de juros, e do nível desta. Convém salientar outro resultado interessante: o efeito do produto industrial sobre o spread bancário. Observou-se que o spread bancário aumenta em decorrência de um choque no produto industrial, possivelmente pelo efeito "poder de mercado" dos bancos. Já o efeito de um choque da taxa de inflação sobre o spread é positivo, mas bem inferior ao de outras variáveis relevantes.

Assim, o spread é influenciado positivamente por um impulso de um desvio padrão na volatilidade da taxa de juros e pela taxa de juros em nível, com efeito persistente em ambos os casos ao

36 O procedimento usado para ordenar as variáveis utilizadas no VAR para a decomposição de Cholesky foi o teste de causalidade de Granger/Block Exogeneity Wald Tests. Este teste é útil no sentido de ordenar as variáveis das mais exógenas para as mais endógenas. Para mais detalhes, consultar Enders (1995); Camuri (2005).

37 Mendonça (2005). 
longo dos 12 meses. O efeito do produto industrial sobre o spread é positivo, ainda que menor do que no caso da volatilidade e nível da taxa de juros. No tocante à inflação, não se observou uma influência significativa sobre o spread.

\section{Figura 6 - Função-resposta do spread a um impulso nas variáveis macroeconômicas}

Response to Cholesky One S.D. Innovations \pm 2 S.E.
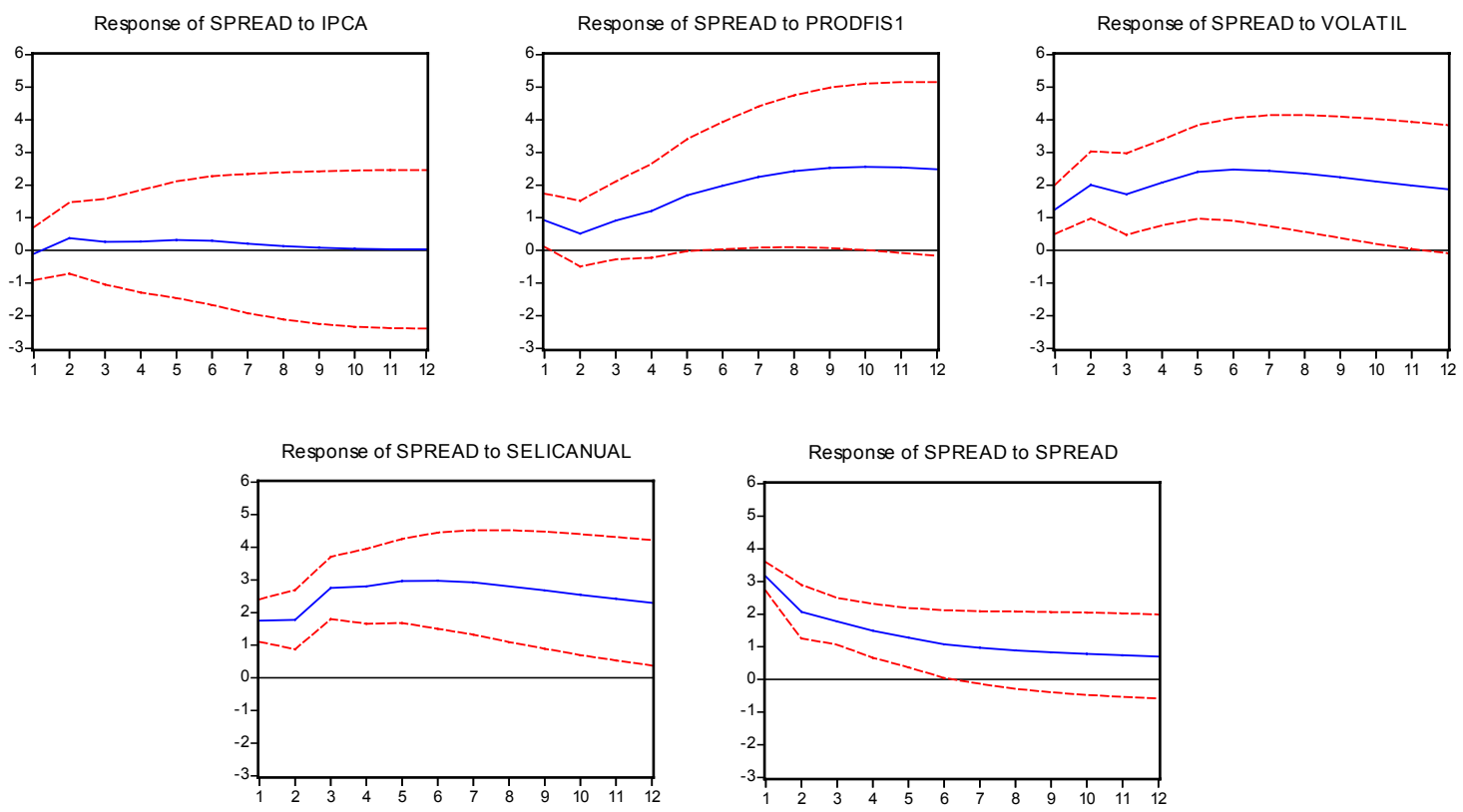

A decomposição da variância dos erros de previsão é uma ferramenta útil por mostrar a evolução do comportamento dinâmico apresentado pelas variáveis em consideração $n$ períodos à frente. A decomposição da variância para doze meses após o choque, conforme se pode observar na Tabela 5, mostra que apenas $13 \%$ do comportamento do spread bancário deve-se a ela própria. A produção física explica $22 \%$ da variação do spread bancário. Vale observar que uma parcela significativa da variação do spread bancário após 12 meses é explicada pela volatilidade da taxa de juros, ou seja, cerca de $26 \%$ da variação total. Entretanto, o efeito da taxa média de juros sobre o spread foi ainda mais intenso: aproximadamente $38 \%$.

Tabela 5 - Decomposição da variância $(\%)$ - spread bancário

\begin{tabular}{|c|c|c|c|c|c|}
\hline Período & IPCA & PRODFIS1 & VOLATIL & SELICANUAL & SPREAD \\
\hline 1 & 0.068494 & 5.471944 & 10.25953 & 19.84482 & 64.35521 \\
\hline 2 & 0.555186 & 4.051210 & 20.53693 & 22.79362 & 52.06305 \\
\hline 3 & 0.526235 & 4.646250 & 20.43995 & 32.93223 & 41.45533 \\
\hline 6 & 0.500006 & 10.48644 & 25.52787 & 40.44465 & 23.04103 \\
\hline 9 & 0.352385 & 17.49832 & 26.30397 & 40.03886 & 15.80647 \\
\hline 12 & 0.269116 & 22.49254 & 25.66667 & 38.80809 & 12.76359 \\
\hline
\end{tabular}

Fonte: Elaboração própria a partir da saída do Eviews 5.

Nota: Cholesky Ordering: IPCA PRODFIS1 VOLATIL SELICANUAL SPREAD. 
Concluindo, os resultados encontrados na decomposição da variância e na função impulsoresposta mostram que os principais determinantes macroeconômicos do spread bancário no Brasil são a volatilidade, o nível da taxa SELIC e a produção física.

\section{CONClusÃo}

Os resultados obtidos dos exercícios econométricos realizados na seção 5 evidenciaram - em consonância com a literatura internacional empírica - que os fatores macroeconômicos são importantes, no Brasil, na explicação da determinação do spread bancário. Em particular, destacam-se: (i) a elevada volatilidade da taxa de juros que, como vimos, eleva o risco de taxa de juros enfrentado pelo banco e aumenta o seu grau de aversão ao risco; (ii) o nível da taxa de juros, que serve tanto como piso para as taxas de empréstimos como "custo de oportunidade" para as operações de empréstimos, em razão da indexação à Selic de parte da dívida pública; (iii) a produção industrial mostrou o efeito poder de mercado prevalecendo sobre o efeito inadimplência, uma vez que uma maior demanda por crédito implicou maiores taxas de empréstimos.

De fato, a incerteza no ambiente macroeconômico que envolve os bancos é uma importante causa dos elevados spreads no Brasil. Se isto é verdade, então a adoção de políticas macroeconômicas consistentes que criem condições para um crescimento econômico sustentável e financeiramente estável poderá ter um efeito positivo em reduzir os spreads bancários no Brasil. ${ }^{38} \mathrm{Sem}$ isto, medidas de natureza microeconômica visando a diminuição do spread poderão se revelar inócuas. Nas palavras de Saunders e Schumacher (2000, p. 815): "if a significant proportion of bank margins in a given country is determined by interest-rate volatility rather than monopolistic behavior by banks, then public policy attention might be better focused on government's macroeconomic policies as a tool for reducing the cost of intermediation services."

\section{REFERÊNCIAS BIBLIOGRÁFICAS}

Afanasieff, T. S.; Lhacer, P. M.; Nakane, M. I. The determinants of bank interest spread in Brazil. Money Affairs, v. XV, n. 2, p. 183-207, 2002.

Allen, L. The determinants of bank interest margins: a note. Journal of Financial and Quantitative Analysis, v. 23, p. 231-235, 1988.

Angbazo, L. Commercial bank net interest margins, default risk, interest-rate risk, and off-balance sheet banking. Journal of Banking and Finance, v. 21, p. 55-87, 1997.

Aronovich, S. Uma nota sobre os efeitos da inflação e do nível de atividade sobre o spread bancário. Revista Brasileira de Economia, v. 48, n. 1, p. 125-140, 1994.

Banco Central do Brasil - BCB. Juros e spread bancário no Brasil. 1999. Disponível em: http://www.bcb. gov.br. Acessado em: 11 de maio de 2004.

Economia bancária e crédito: avaliação de 3 anos do Projeto Juros e Spread Bancário. 2002. Disponível em: http://www.bcb.gov.br. Acessado em: 11 de maio de 2004.

Economia bancária e crédito: avaliação de 5 anos do Projeto Juros e Spread Bancário. 2004. Disponível em: http://www.bcb.gov.br. Acessado em: 21 de setembro de 2005.

Belaisch, A. Do Brazilian banks compete? IMF Working Paper WP/03/113, 2003.

38 Nossa avaliação é que não há razões para supor que a economia brasileira está entrando em uma rota de crescimento sustentado. (Oreiro et al., 2003). Extrapola, contudo, os objetivos deste artigo aprofundar esta questão. 
Brock, P. L.; Suarez, L. R. Understanding the behavior of bank spreads in Latin America. Journal of Development Economics, v. 63, p. 113-134, 2001.

Camuri, P. A. Dívida pública, política fiscal e vulnerabilidade externa no Brasil. 2005. Dissertação (Mestrado), CEDEPLAR/UFMG, Belo Horizonte.

Coutinho, R. Spread e concentração bancária no Brasil. Monografia de conclusão do curso de Ciências Econômicas. Curitiba: CSA/UFPR, 2003.

Demirguç-Kunt, A.; Huizinga, H. Determinants of commercial bank interest margins and profitability: some international evidence. The World Bank Economic Review, v. 13, n. 2, 1999.

Enders, W. Applied econometric time series. New York: Jonh Wiley \& Sons, 1995.

Freixas, X.; Rochet, J. Economía bancaria. Barcelona: Antoní Bosch, 1999.

Granger, C. W. J. Investigating causal relations by econometric models and cross-spectral methods. Econometrica, v. 37, p. 424-438, 1969.

Groppo, G. Causalidade das variáveis macroeconômicas sobre o IBOVESPA. 2004. Dissertação (Mestrado), ESALQ/USP, Piracicaba.

Ho, T. S. Y.; Saunders, A. The determinants of bank interest margins: theory and empirical evidence. Journal of Financial and Quantitative Analysis, v. 16, p. 581-600, 1981.

IBGE/DECNA. Sistema financeiro: uma análise a partir das contas nacionais, 1990-1995. Rio de Janeiro: IBGE/DECNA, 1997.

IEDI. Spread no Brasil e no mundo. Carta n. 100. 2004. Disponível em: http://www.iedi.org.br. Acessado em: 18 de maio de 2004.

IMF - International Monetary Fund. International capital markets: developments, prospects, and key policy issues. Washington: IMF, 2001.

Klein, M. A. A theory of the banking firm. Journal of Money, Credit and Banking, v. 3, n. 2, p. 205-218, 1971.

Koyama, S. M.; Nakane, M. I. Os determinantes do spread bancário no Brasil. In: Banco Central do Brasil, juros e spread bancário no Brasil: avaliação de 2 anos do projeto. Brasília: Banco Central do Brasil, 2001, p. 27-30.

Malaga, T.; Maziero, P.; Werlang, S. R. C. Estudo de rentabilidade bancária. Consultoria Econômica do Banco Itaú - Informe Especial. São Paulo: Banco Itaú, 2003.

Manual do Eviews. EViews 5 User's Guide. 2004. Disponível em: http://www.eviews.com.

Maudos, J.; Guevara, J. F. Factors explaining the interest margin in the banking sectors of the European Union. Journal of Banking and Finance, v. 28, n. 9, 2004.

McShane, R. W.; Sharpe I. G. A time series/cross section analysis of the determinants of Australian trading bank loan/deposit interest margins: 1962-1981. Journal of Banking and Finance, v. 9, p. 115-136, 1985.

Mendes, R. Taxas de empréstimos e spreads bancários no Brasil: implicações e causas do alto nível dos spreads. Monografia de conclusão do curso de Ciências Econômicas. Rio de Janeiro: FCE/UERJ, 2004.

Mendonça, H. F. Metas para inflação e variáveis macroeconômicas: uma avaliação empírica. Anais do XXXIII Encontro Nacional de Economia - ANPEC, 2005.

Nakane, M. I. A test of competition in Brazilian banking. Estudos Econômicos, v. 32, n. 2, p. 203-224, abr./jun. 2002.

. Concorrência e spread bancário: uma revisão da evidência para o Brasil. In: Banco Central do Brasil, juros e spread bancário no Brasil: avaliação de 4 anos do projeto. Brasília: Banco Central do Brasil, 2003, p. 58-67.

Nakane, M. I.; Costa, A. C. A. Spread bancário: os problemas da comparação internacional. Risk Update, Ano 1, n. 3, p. 9-14, 2005. 
Oliveira, G. C. Análise do spread bancário no Brasil após o Plano Real (1994-2003). 2004. Dissertação (Mestrado), PUC-SP, São Paulo.

Oreiro, J. L.; Sicsú, J.; Paula, L. F. Controle da dívida pública e política fiscal: uma alternativa para um crescimento auto-sustentado da economia brasileira. In: Sicsú, J.; Oreiro, J. L.; Paula, L. F. (orgs.), Agenda Brasil: políticas econômicas para o crescimento com estabilidade de preços. Barueri/SP: Manole, 2003.

Oreiro, J. L. Preferência pela liquidez, racionamento de crédito e concentração bancária: uma nova teoria pós-keynesiana da firma bancária. Estudos Econômicos, v. 35, n. 1, p. 101-131, jan./mar. 2005.

Paula, L. F. Dinâmica da firma bancária: uma abordagem não-convencional. Revista Brasileira de Economia, v. 53, n. 3, p. 323-356, 1999.

Paula, L. F.; Alves Jr., A. J. Banking behaviour and the Brazilian economy after the Real Plan: a postKeynesian approach. Banca Nazionale del Lavoro Quarterly Review, n. 227, p. 337-365, 2003.

Paula, L. F.; Alves Jr., A.; Marques, M. B. L. Ajuste patrimonial e padrão de rentabilidade dos bancos privados durante o Plano Real (1994/98). Estudos Econômicos, v. 31, n. 2, p. 285-319, abr./jun. 2001.

Saunders, A.; Schumacher, L. The determinants of bank interest rate margins: an international study. Journal of International Money and Finance, v. 19, p. 813-832, 2000.

\section{APÊNDICE}

\begin{tabular}{|c|c|c|c|c|c|}
\hline \multicolumn{6}{|c|}{$\begin{array}{l}\text { Vector Autoregression Estimates } \\
\text { Sample (adjusted): 1995M03 2003M12 } \\
\text { Included observations: } 106 \text { after adjustments } \\
\text { Standard errors in ( ) \& t-statistics in [ ] }\end{array}$} \\
\hline & IPCA & PRODFIS & VOLATIL & SELICANUAL & SPREAD \\
\hline \multirow[t]{3}{*}{$\operatorname{IPCA}(-1)$} & 0.612880 & -0.754704 & -0.000409 & 0.335401 & 0.745797 \\
\hline & $(0.10164)$ & $(1.44720)$ & $(0.00297)$ & (1.19757) & $(0.85293)$ \\
\hline & [ 6.02995] & {$[-0.52149]$} & {$[-0.13798]$} & [0.28007] & [ 0.87439] \\
\hline \multirow[t]{3}{*}{$\operatorname{IPCA}(-2)$} & -0.101242 & -0.019087 & -0.003691 & -0.739534 & -0.183782 \\
\hline & $(0.10186)$ & $(1.45035)$ & $(0.00297)$ & $(1.20018)$ & $(0.85479)$ \\
\hline & [-0.99392] & {$[-0.01316]$} & {$[-1.24196]$} & {$[-0.61618]$} & {$[-0.21500]$} \\
\hline \multirow[t]{3}{*}{ PRODFIS(-1) } & -0.006020 & 0.640008 & 0.000519 & 0.193943 & 0.164365 \\
\hline & $(0.00737)$ & $(0.10495)$ & $(0.00022)$ & $(0.08685)$ & $(0.06185)$ \\
\hline & {$[-0.81671]$} & [ 6.09822] & [ 2.41475] & [ 2.23314] & [ 2.65729] \\
\hline \multirow[t]{3}{*}{ PRODFIS(-2) } & 0.007717 & -0.074606 & -0.000237 & -0.066453 & -0.098365 \\
\hline & $(0.00762)$ & $(0.10848)$ & $(0.00022)$ & $(0.08977)$ & $(0.06393)$ \\
\hline & [ 1.01289$]$ & {$[-0.68776]$} & {$[-1.06572]$} & {$[-0.74030]$} & {$[-1.53856]$} \\
\hline \multirow[t]{3}{*}{ VOLATIL(-1) } & 1.640594 & -35.17989 & -0.156687 & -189.2409 & -43.07993 \\
\hline & (6.32296) & $(90.0296)$ & $(0.18449)$ & $(74.5007)$ & (53.0608) \\
\hline & [ 0.25947] & {$[-0.39076]$} & {$[-0.84929]$} & {$[-2.54012]$} & {$[-0.81190]$} \\
\hline
\end{tabular}




\begin{tabular}{|c|c|c|c|c|c|}
\hline \multirow[t]{3}{*}{ VOLATIL(-2) } & 2.971450 & 6.421604 & 0.093703 & 76.86194 & -41.08328 \\
\hline & $(5.46885)$ & (77.8683) & $(0.15957)$ & (64.4371) & $(45.8933)$ \\
\hline & [0.54334] & [ 0.08247] & [0.58723] & [1.19282] & {$[-0.89519]$} \\
\hline \multirow[t]{3}{*}{ SELICANUAL(-1) } & 0.009976 & -0.182404 & 0.001469 & 1.274210 & 0.493104 \\
\hline & $(0.01759)$ & $(0.25046)$ & $(0.00051)$ & $(0.20726)$ & $(0.14761)$ \\
\hline & [0.56712] & {$[-0.72828]$} & [ 2.86186] & [6.14794] & [ 3.34052] \\
\hline \multirow[t]{3}{*}{ SELICANUAL(-2) } & -0.009647 & -0.028923 & -0.000935 & -0.300563 & -0.026932 \\
\hline & $(0.01642)$ & $(0.23379)$ & $(0.00048)$ & $(0.19346)$ & $(0.13779)$ \\
\hline & {$[-0.58755]$} & {$[-0.12371]$} & [-1.95107] & {$[-1.55360]$} & {$[-0.19546]$} \\
\hline \multirow[t]{3}{*}{ SPREAD(-1) } & -0.002971 & 0.483901 & -0.000509 & -0.279894 & 0.499233 \\
\hline & $(0.01337)$ & $(0.19041)$ & $(0.00039)$ & $(0.15756)$ & $(0.11222)$ \\
\hline & {$[-0.22219]$} & [ 2.54141] & [-1.30549] & [-1.77639] & [ 4.44871] \\
\hline \multirow[t]{3}{*}{ SPREAD(-2) } & 0.012427 & -0.394506 & 0.000499 & 0.269252 & 0.289456 \\
\hline & $(0.01207)$ & $(0.17180)$ & $(0.00035)$ & $(0.14216)$ & $(0.10125)$ \\
\hline & [1.02992] & [-2.29634] & [ 1.41612] & [ 1.89394] & [ 2.85876] \\
\hline \multirow[t]{3}{*}{ C } & 0.425493 & 55.35693 & -0.042916 & -16.68920 & -9.104072 \\
\hline & $(0.90126)$ & $(12.8325)$ & $(0.02630)$ & (10.6191) & $(7.56312)$ \\
\hline & [ 0.47211] & [ 4.31379] & [-1.63200] & [-1.57162] & {$[-1.20375]$} \\
\hline \multirow[t]{3}{*}{ COMPULS } & -1.354015 & -12.01059 & 0.011460 & 7.470524 & 1.954989 \\
\hline & $(0.50754)$ & (7.22662) & $(0.01481)$ & $(5.98012)$ & $(4.25915)$ \\
\hline & [-2.66780] & [-1.66199] & [ 0.77386$]$ & [1.24923] & [ 0.45901$]$ \\
\hline R-squared & 0.603736 & 0.604106 & 0.280424 & 0.847157 & 0.986281 \\
\hline Adj. R-squared & 0.557365 & 0.557778 & 0.196218 & 0.829271 & 0.984675 \\
\hline Sum sq. resids & 17.17292 & 3481.561 & 0.014620 & 2384.094 & 1209.345 \\
\hline S.E. equation & 0.427423 & 6.085876 & 0.012471 & 5.036140 & 3.586833 \\
\hline F-statistic & 13.01961 & 13.03973 & 3.330221 & 47.36448 & 614.3253 \\
\hline Log likelihood & -53.94190 & -335.4727 & 320.6987 & -315.4037 & -279.4304 \\
\hline Akaike AIC & 1.244187 & 6.556089 & -5.824504 & 6.177428 & 5.498687 \\
\hline Schwarz SC & 1.545708 & 6.857610 & -5.522982 & 6.478949 & 5.800208 \\
\hline Mean dependent & 0.720094 & 106.4944 & 0.004999 & 26.31198 & 59.84302 \\
\hline S.D. dependent & 0.642444 & 9.151719 & 0.013910 & 12.18832 & 28.97422 \\
\hline \multicolumn{2}{|c|}{ Determinant resid covariance (dof adj.) } & 0.059646 & & & \\
\hline \multicolumn{2}{|c|}{ Determinant resid covariance } & 0.032711 & & & \\
\hline \multicolumn{2}{|l|}{ Log likelihood } & -570.7746 & & & \\
\hline \multicolumn{2}{|c|}{ Akaike information criterion } & 11.90141 & & & \\
\hline \multicolumn{2}{|l|}{ Schwarz criterion } & 13.40901 & & & \\
\hline
\end{tabular}

